\title{
ESTRATIGRAFIA E CORRELAÇÕES DA BACIA DE POUSO ALEGRE, TRANSIÇÃO NEOPROTEROZÓICO-CAMBRIANO, MINAS GERAIS, BRASIL
}

\author{
Antonio Luiz TEIXEIRA \\ Setembrino PETRI
}

\section{RESUMO}

Os depósitos sedimentares da região de Pouso Alegre e outros remanescentes de bacias eminentemente terrígenas ocorrem ao longo do Cinturão Ribeira, desde o Estado de Minas Gerais até o Paraná. A análise das fácies sedimentares e dos sistemas deposicionais permitiram discriminar na bacia de Pouso Alegre três unidades estratigráficas representadas por associações de fácies que caracterizam depósitos subaéreos de leques aluviais; depósitos deltaicos (fan-delta) e depósitos de plataforma proximal. Nos ambientes subaquosos, esses depósitos foram retrabalhados pela ação de correntes de marés, por ondas normais e, eventualmente, de tempestades. Nos depósitos prodeltaicos foram identificados os acritarcos Soldadophycus bossii GAUCHER et al. 1996, Soldadophycus major GAUCHER 2000 e Symplassosphaeridium sp., evidenciando a participação de águas marinhas relativamente bem oxigenadas durante a sedimentação. A correlação com as demais bacias que ocorrem ao longo do Cinturão Ribeira e com outras dos continentes sul-americano e africano é proposta, tendo-se em conta parâmetros estratigráficos, paleontológicos e geocronológicos. Adaptou-se um modelo paleotectônico e paleogeográfico para a evolução do Gondwana Ocidental durante a transição NeoproterozóicoCambriano, em cujo cenário interagiram blocos cratônicos, a colagem de terrenos alóctones e a abertura e fechamento dos oceanos. Após a glaciação Varanger ( $600 \mathrm{Ma})$ e com o aumento das temperaturas do planeta, o nível dos oceanos encontrava-se em ascensão. As águas do Oceano Brazilides penetraram pelas regiões subsidentes meridionais do Cinturão Ribeira, constituindo nível de base para a deposição em bacias extensionais nas porções ocidentais do Orógeno Mantiqueira. Concomitante a estes embaciamentos em mares epicontinentais ocorria a sedimentação em bacias de margens passivas, às bordas dos crátons. A conexão entre os oceanos Brazilides e Adamastor permitiu a disseminação de microfósseis similares, notadamente Cloudina, em quase todas elas. Com a convergência dos blocos cratônicos e o fechamento dos oceanos, ao redor de $530 \mathrm{Ma}$, as bacias sofreram inversão e encurtamento, como assinalado nas assinaturas isotópicas de rochas do embasamento e dos depósitos.

Palavras-chave: bacia terrígena, leque aluvial costeiro, Neoproterozóico-Cambriano, Gondwana Ocidental, correlações.

\section{ABSTRACT}

Remnants of Pouso Alegre and other essentially terrigenous basin deposits occur along the Ribeira Belt from Minas Gerais to Paraná State. Analysis of sedimentary facies and depositional systems allowed discrimination of three stratigraphic units represented by deposits related to subaerial alluvial fans, fan-delta and proximal shelf. In subaqueous environments these deposits were reworked by tidal currents and by normal or, eventually, storm waves. The acritarchs Soldadophycus bossii GAUCHER et al. 1996, Soldadophycus major GAUCHER 2000 e Symplassosphaeridium sp. were identified in the prodeltaic sediments, denoting participation of relatively oxygenated marine waters during sedimentation. Taking into account stratigraphic, paleontological and geochronological parameters, it is proposed that a correlation exists with the other basins along the Ribeira Belt, as well with others in Africa and South America. A palaeotectonic and palaeogeographic model was adapted to the evolution of the Western Gondwana during the Neoproterozoic-Cambrian transition, in a scenario where cratonic blocks, tectonic collage and opening and closing of the oceans interacted. After the Varanger glacial event ( $\mathrm{ca} 600 \mathrm{Ma}$ ) and the rising of the planet temperatures, ocean levels were also rising. Brazilides Ocean waters penetrated the southern subsiding areas of the Ribeira Belt and became a base level for infillings of strike-slip basins in the occidental areas of the Mantiqueira Orogen. Concomitant to these epicontinental basin infillings, sedimentation was also taking place in passive basins of the cratonic marginal areas. The connection between the Brazilides and Adamastor oceans allowed dispersion of similar microfossils, mainly Cloudina, in almost all basins. Convergence of cratonic blocks and closure of the oceans near $530 \mathrm{Ma}$ allowed basin inversions, as revealed by isotopic signatures of basement and basin rocks.

Keywords: terrigenous basin, fan-delta, Neoproterozoic-Cambrian, Western Gondwana, correlations. 


\section{INTRODUÇÃO}

Desde o sul de Minas Gerais, passando por São Paulo, até a região de Curitiba, no Paraná, ocorre uma série de depósitos remanescentes de bacias pretéritas com pequenas dimensões em área que escaparam dos sucessivos eventos erosivos fanerozóicos, graças ao condicionamento imposto pelas zonas de cisalhamento que recortam o Cinturão Ribeira na porção sul-sudeste do Brasil. No sul de Minas Gerais (FIGURA 1), um destes remanescentes metamorfismo predominante de muito baixo grau (WINKLER 1976) e pela ausência de magmatismo sin-sedimentar. Por outro lado, incorporam, como fragmentos clásticos, quase a totalidade das rochas discrimináveis do embasamento. Localmente, mostram-se sobrepostos pelos sedimentos fanerozóicos da bacia do Paraná, através de discordâncias angular e erosiva.

Ainda persiste muita dúvida sobre quais e quantos embaciamentos existiram ao longo do Cinturão Ribeira na região e sobre quais daqueles

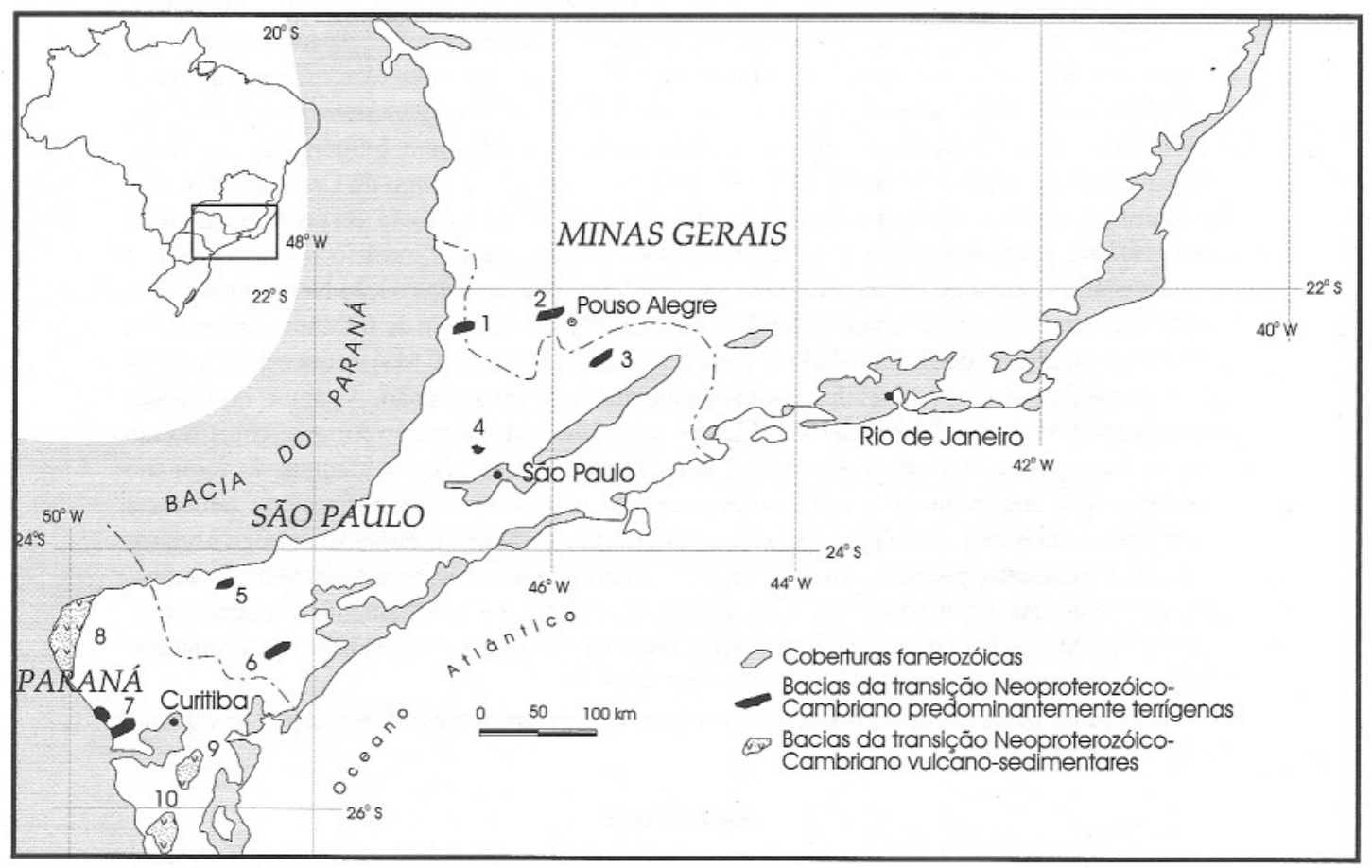

FIGURA 1 - Localização das bacias da transição Neoproterozóico-Cambriano eminentemente terrígenas e vulcanosedimentares, entre os estados de Minas Gerais e Paraná, com destaque para a bacia de Pouso Alegre. Bacias eminentemente terrígenas: 1. Eleutério, 2. Pouso Alegre, 3. Pico de Itapeva, 4. Cajamar, 5. Samambaia, 6. Quatis e 7. Camarinha. Bacias vulcano-sedimentares: 8. Castro, 9. Guaratubinha e 10. Campo Alegre.

ocorre a poucos quilômetros da cidade de Pouso Alegre. Nas regiões limítrofes deste estado com o de São Paulo ocorrem os depósitos de Eleutério. Ainda, e totalmente no Estado de São Paulo, ocorrem os remanescentes do Pico de Itapeva, de Cajamar, do Samambaia e do Quatis. E, finalmente, no Paraná, na Região Metropolitana de Curitiba, ocorrem os depósitos do Camarinha. Os depósitos são caracterizados pela imaturidade textural e mineralógica, por seus limites tectônicos com o embasamento mais antigo e pela rápida variação lateral e vertical de fácies, desenvolvidas em ambientes subaéreos a subaquosos. Diferenciamse das rochas do embasamento por apresentarem seriam contínuos ou apenas contíguos. Assim, deve ser ressaltado que cada remanescente isolado pode representar resquício ímpar de uma determinada bacia. De outro modo, alguns dos remanescentes podem constituir resquícios de uma mesma bacia em que pode, ou não, haver correspondência entre os horizontes (crono)estratigráficos que representam. Com o intuito de evitar a proliferação de novas denominações estratigráficas, até que os avanços de conhecimentos permitam fazê-lo mais adequadamente, optou-se por denominar informalmente esses remanescentes de "bacia", seguida da antiga denominação toponímica proposta pelos autores, ao categorizá-los como "formação". ou "grupo". 
A análise estratigráfica baseou-se nas fácies sedimentares e suas associações e nos sistemas deposicionais envolvidos. A análise estrutural constituiu ferramenta importante para o estabelecimento das relações entre os depósitos e o embasamento e para o fornecimento de subsídios para a compreensão dos aspectos deformacionais dos pacotes, seja com relação àqueles relacionados com a fase de inversão e encurtamento da bacia ou com aqueles mais tardios. Onde possível utilizouse de análises paleontológicas, litogeoquímicas e geocronológicas para subsidiar a análise estratigráfica e as correlações entre as bacias.

Os remanescentes da bacia de Pouso Alegre ocorrem a pouco mais de $3 \mathrm{~km}$ a noroeste da cidade de mesmo nome, no sul de Minas Gerais, ocupando regiões de topo e encosta da Serra do Santo Antônio, em área aproximada de 4,6 km2. Esses depósitos foram descritos por LEONARDOS JUNIOR et al. (1971), recebendo destes a denominação de "Formação Pouso Alegre", constituída por uma seqüência gradativa, da base para o topo, de metaconglomerados polimíticos, metassiltitos, metamargas e metarenitos feldspáticos e metarcóseos. Segundo os autores, os depósitos foram metamorfisados na fácies xisto-verde, a par de metamorfismo retrógrado das rochas do embasamento. A deposição, ainda segundo os mesmos autores, teria ocorrido em ambientes rasos de sedimentação, provavelmente deltaico, durante o Neoproterozóico.

A idade para a sedimentação na bacia de Pouso Alegre, a partir de datações absolutas, ainda não foi suficientemente estabalecida. HAMA \& CUNHA (1977) obtiveram em metassiltitos calcíferos, pelo método K-Ar, idades de $524 \pm 20$ $\mathrm{Ma}$, em rocha total, e idades de $485 \pm 15 \mathrm{Ma}$, pelo mesmo método, em biotita+sericita da mesma amostra, que poderiam indicar idades mínimas para a sedimentação.

Baseando-se nos resultados obtidos e nas correlações estratigráficas e bioestratigráficas com outras bacias, propõe-se que a sedimentação na bacia de Pouso Alegre ocorreu no intervalo de 570$540 \mathrm{Ma}$, intervalo referenciado principalmente na ocorrência do microfóssil Cloudina riemkeae GERMS 1972, descrito nas bacias de Eleutério (SPMG), de Corumbá (MS), do Arroyo del Soldado (Uruguai) e do Nama (Namíbia).

A inversão e encurtamento da bacia de Pouso Alegre ocorreram ao redor de $530 \mathrm{Ma}$, conforme assinaturas isotópicas $\mathrm{K}-\mathrm{Ar}$ de biotitas do embasamento e, em rocha total, de seixos de riólitos de metaconglomerados da bacia de Eleutério e de metassiltitos da bacia de Pouso Alegre, que refletem o resfriamento regional.

\section{CONTEXTOGEOLÓGICO}

Os remanescentes da bacia de Pouso Alegre ocorrem embutidos entre falhas pertencentes à Zona de Cisalhamento Transcorrente de Monte Sião (CAMPOS NETO 1991) que atravessa, no sul do Estado de Minas Gerais, os terrenos do Cinturão Alto Rio Grande (HASUI 1982). Na região, as rochas que compõem este cinturão estão expostas ao longo de corredor relativamente estreito, com direção NE-SW, entre os terrenos do sistema de nappes Socorro-Guaxupé (CAMPOS NETO 1991), limitado, grosso modo, pelas zonas de cisalhamento transcorrente de Monte Sião e de Três Corações (CAMPOS NETO 1991), a sudeste e noroeste, respectivamente.

$\mathrm{Na}$ região, o Cinturão Alto Rio Grande constitui um empilhamento de rochas infracrustais e supracrustais, de natureza vulcano-sedimentar e filiação cálcio-alcalina (CAMPOS NETO \& FIGUEIREDO 1995), representadas por quartzitos, xistos variados, por vezes migmatizados, gnaisses orto- e paraderivados, granitóides e migmatitos de anatexia e metabasitos, além de milonitos derivados da quase totalidade destas rochas.

\section{ESTRATIGRAFIA}

A bacia remanescente tem forma aproximadamente triangular isósceles (FIGURA 2) com a base, grosso modo, orientada segundo a direção E-W. Os seus limites são dados por falhas que constituem ramificações da Zona de Cisalhamento Transcorrente de Monte Sião (CAMPOS NETO 1991) que corta, na região, embasamento atribuído ao Cinturão Alto Rio Grande (HASUI 1982).

Os depósitos apresentam estruturas sedimentares bem preservadas, com estratos sempre mergulhando para sudeste com média aproximada de $30^{\circ}$, para onde também se dirige, invariavelmente, o topo das camadas. A espessura total dos pacotes atinge cerca de $1050 \mathrm{~m}$. Foram distinguidas três unidades estratigráficas na bacia que, da base para o topo (de NW para SE), são constituídas por associações de fácies que se intercalam, ocorrendo em cada unidade o predomínio de umas sobre outras, o que permitiu discriminá-las genericamente como: 1 . Unidade com 


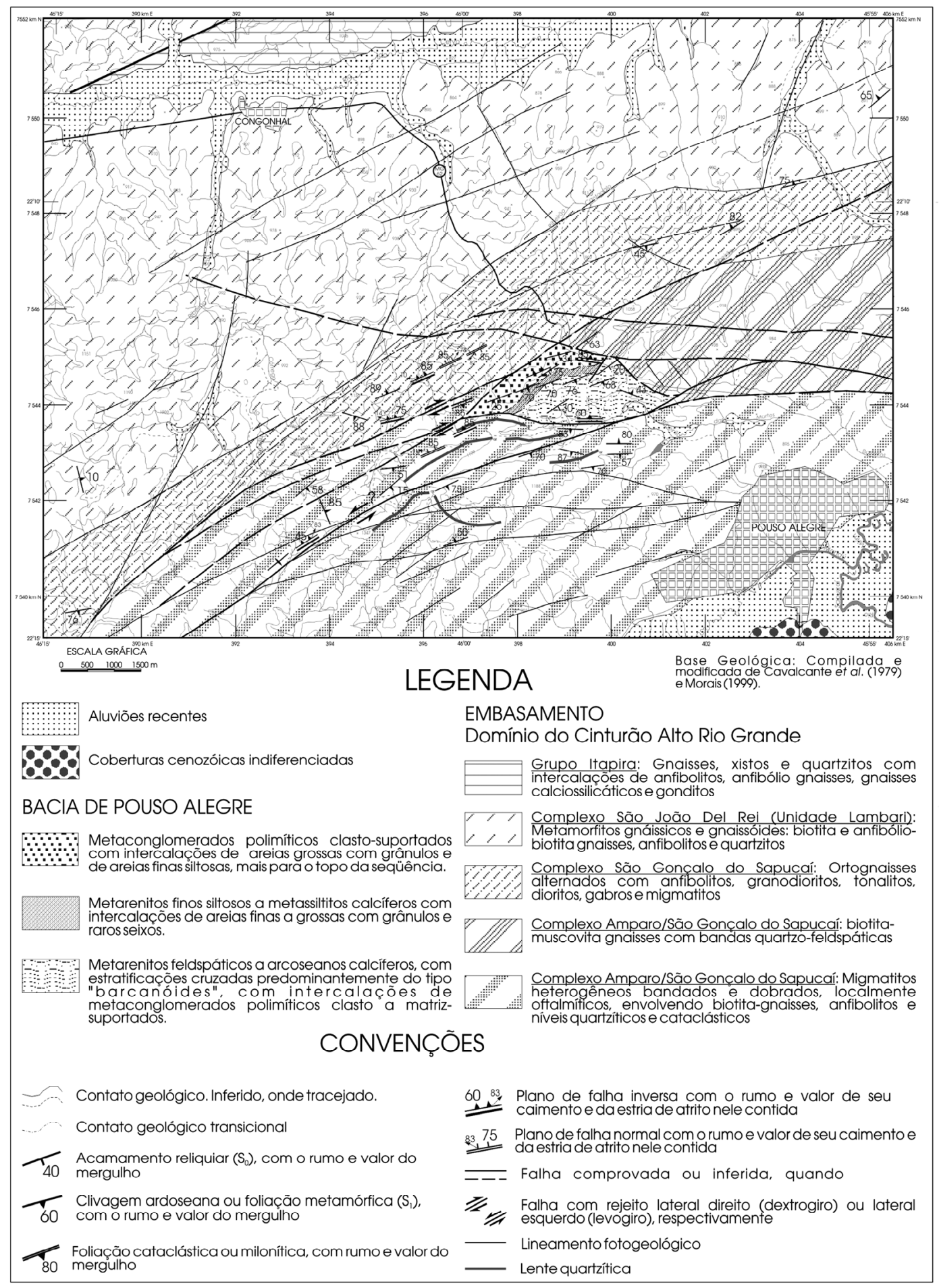

FIGURA 2 - Mapa das associações de fácies da bacia de Pouso Alegre.

predomínio de fácies de metaconglomerados polimíticos e de metarenitos mal selecionados, 2 . Unidade com predomínio de fácies de metarenitos finos a metassiltitos calcíferos e 3 . Unidade com predomínio de fácies de metarenitos feldspáticos e arcoseanos.
3.1 Unidade com predomínio de fácies de metaconglomerados polimíticos e de metarenitos mal selecionados

Os depósitos desta unidade ocupam a base da bacia e seus limites com o embasamento 
gnáissico-migmatítico, a noroeste, ocorrem através de falhas. O pacote sedimentar tem espessura aproximada de $280 \mathrm{~m}$. Os depósitos organizam-se em estratos tabulares (traction carpets, no sentido de TODD 1989) com espessuras que variam de 0,4 a 1 m (FIGURA 3). Da base para o topo, ocorre gradação normal com maior concentração de matacões na base, calhaus na porção média e seixos e grânulos na porção final. Esta seqüência é sucedida, transicional ou erosivamente, por fácies de metarenitos mal selecionados com estratificação/ laminação plano-horizontal, cujas espessuras raramente ultrapassam os $0,2 \mathrm{~m}$ e, geralmente, apresentam-se rompidas devido à sobrecarga (pullapart structures) ou interrompidas pela erosão. Os metaconglomerados polimíticos são predominantemente clasto-sustentados, com o arcabouço constituído por clastos que variam de matacões a grânulos, predominando calhaus e seixos arredondados a subarredondados de gnaisses e migmatitos milonitizados, granitos e granitóides, xistos e quartzitos, metabasitos, quartzo de veio e pegmatóides. A imbricação é comum na fração calhau, mas predomina a isorientação dos clastos maiores e oblatos ao longo do acamamento. A matriz é arenosa lítica, feldspática a arcoseana, ocupando os espaços interclásticos e é constituída de fragmentos líticos, feldspatos, biotita, turmalina, anfibólio, muscovita e opacos, além de minerais neoformados por dissolução por pressão intragranular, como illita, clorita e sericita. Em microfraturas, ocorre o epídoto e, subordinadamente, a calcita. Como cimento, pode ocorrer a calcita sintaxial.

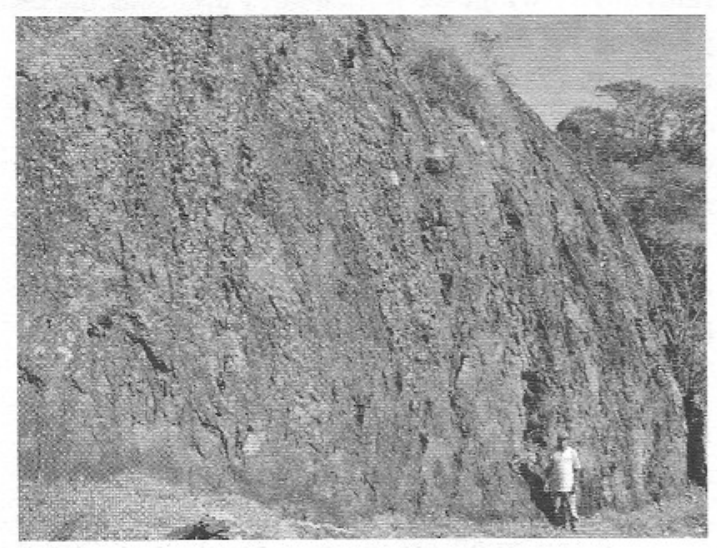

FIGURA 3 - Metaconglomerado polimítico clastosustentado organizado em tapetes de tração (traction carpets), com espessura métrica a decimétrica, com definição de tapetes onde predomina a granulação matacões e calhaus (na altura da escala) e tapetes com predomínio da granulação calhaus e seixos, na porção central. Topo para a esquerda da foto (SE).
Nas porções de topo, ou distais da unidade, os metaconglomerados são intercalados ritmicamente por associação de fácies de metarenitos e metassiltitos com metargilitos que, a partir de alguns centímetros nas porções basais, superam 1 m de espessura em direção ao topo da seqüência (fining e thickening-upward). Estas fácies assentam-se erosivamente sobre as fácies de metaconglomerados e de areias mal selecionadas associadas e são constituídas, na base, por areias mal selecionadas com estratificações cruzadas de pequeno porte. Gradam rapidamente, em direção ao topo, para metarenitos médios a finos com estratificação plano-horizontal suavemente ondulada. Estes, por sua vez, transicionam para fácies de metarenitos finos siltosos, recobertos por lâmina argilosa, que apresentam, em direção ao topo, ondulações assimétricas, simétricas e ondulações plano-horizontais e, às vezes, cruzadas de baixo ângulo e hummocky cross stratification (FIGURA 4). Uma outra seqüência desta associação de fácies pode recorrer, mas, em geral, sucede-lhe um novo

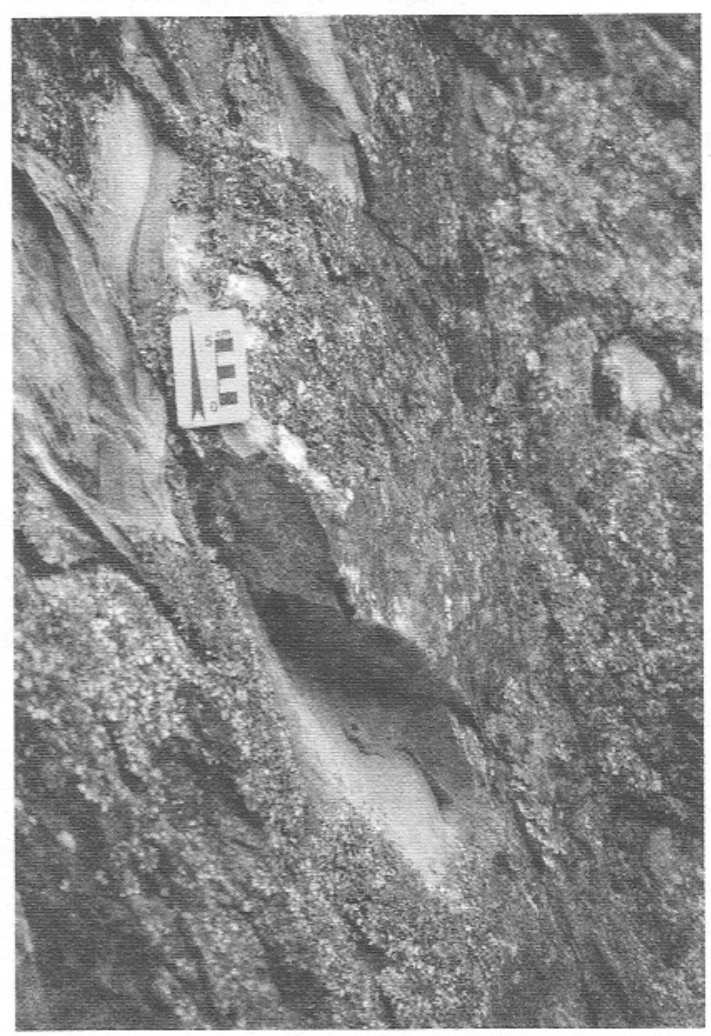

FIGURA 4 - Estrutura amendoada em metarenitos finos siltosos laminados, com $0,7 \mathrm{~m}$ de diâmetro, relacionada a ondas de tempestades (hummocky cross stratification), intercalados em metaconglomerados polimíticos das porções distais de leque aluvial progradante em corpo aquoso marinho (fan-delta). 
fluxo de metaconglomerados, paulatinamente com menor espessura e com granulação mais fina, na medida que se aproxima do topo da unidade, até que se definem outras unidades faciológicas com características próprias, descritas à frente.

\subsubsection{Interpretação}

A associação de fácies de metaconglomerados polimíticos e metarenitos mal selecionados organizados em tapetes de tração representa fluxos densos subaéreos, associados a leques aluviais desenvolvidos a partir de regiões escarpadas. Distalmente, as franjas desses leques sofreram paulatino afogamento ao encontrar corpo d'água marinho raso, definindo construções deltaicas de granulação grossa (fan-delta, sensu MCPHERSON et al. 1987), atingindo até as regiões de antepraia (shoreface) onde foram retrabalhadas, com a concomitante deposição de fácies arenosa a siltoargilosas, sob a ação de correntes de marés, de ondas normais e de tempestades. As porções distais da seqüência evidenciam início de transgressão marinha e/ou retrogradação deltaica/aluvial (FIGURA 5) com a concomitante diminuição no aporte de detritos.

3.2 Unidade com predomínio de fácies de metarenitos finos e metassiltitos calcíferos

Esta unidade atinge espessuras de até 120 $\mathrm{m}$. A sua base tem início com fácies de metassiltitos cinza-claro e de metargilitos cinza-escuro laminados, com gradação normal dos primeiros para os últimos, constituindo estratos cujas espessuras variam entre 1 a $4 \mathrm{~cm}$ com estratificações cruzadas de baixo ângulo, que se sucedem ritmicamente. Estes são intercalados, de modo erosivo na base e topo e, às vezes, também ritmicamente, por fácies de metarenitos mal selecionados e conglomeráticos (grânulos e seixos esparsos), com estratos de espessura de alguns milímetros até $5 \mathrm{~cm}$, apresentando gradação normal e estratificação cruzada de pequeno porte.

Nas porções médias da unidade, e em direção ao topo, predominam fácies de metassiltito argiloso laminado com intercalações de metarenito muito fino, localmente com cristais idiomórficos de pirita, com ondulações cavalgantes (climbing ripple cross lamination), estratificação lenticular (linsen) eflaser.

Próximo ao topo da unidade passa a predominar fácies de metarenitos muito finos com metassiltitos e metargilitos. Os termos arenosos são cinza-claro esbranquiçado e graduam, para o topo, para metassiltitos com tonalidades cinza-claro a médio, quando são recobertos por fina lâmina de metargilito cinza-escuro. Esta seqüência varia desde alguns centimétricos até poucos milímetros de espessura. Nos metarenitos é freqüente o desenvolvimento de ondulações assimétricas com lâminas frontais de alto ângulo $\left(>20^{\circ}\right)$, onde ocorre a gradação normal até metargilitos cinza-escuro (FIGURA 6). As estruturas sedimentares comuns são a estratificação lenticular e, mais rara, do tipo flaser.

Localmente, e em níveis isolados, pequenas convoluções (slumps) podem ser observadas. Também, localmente, desenvolvem-se níveis com espessuras decimétricas onde há o predomínio de metarenitos muito finos laminados, com estratificação cruzada de baixo ângulo, às vezes com truncamentos sugestivos da participação de ondas de tempestades. Deformações de sobrecarga são comuns no pacote, às vezes falseando ondulações. Neste caso, estruturas de escape de fluidos (dish) quase sempre se associam. Nesta fácies TEIXEIRA (2000) relatou a ocorrência dos acritarcos Soldadophycus major GAUCHER 2000 e Symplassosphaeridium sp. (FIGURAS 7 e 8 ) e TEIXEIRA \& GAUCHER (2001) relataram a ocorrência do acritarco Soldadophycus bossii GAUCHER et al. 1996, todos descritos também nas rochas do Grupo Arroyo del Soldado (GAUCHER et al. 1996), no Uruguai (GAUCHER \& SPRECHMANN 1999 e GAUCHER 2000).

\subsubsection{Interpretação.}

Nesta seqüência o aporte continental (aluvial) restringe-se a incursões arenosas até às porções médias da unidade, em ambiente de antepraia (shoreface). O máximo transgressivo (FIGURA 5) é atingido, configurando a decantação de material areno-silto-argiloso, sujeito ao retrabalhamento por ondas normais e de tempestade, em um ambiente de antepraia (shoreface) transicional a plataforma rasa (offshore) com águas oxigenadas (acritarcos) a pouco oxigenadas (cristais de pirita).

3.3 Unidade com predomínio de fácies de metarenitos feldspáticos e arcoseanos

A passagem da unidade dos metarenitos e siltitos calcíferos para a unidade de metarenitos feldspáticos a arcoseanos, apesar de gradativa, ocorre de forma brusca. Esta unidade atinge espessuras de cerca de $650 \mathrm{~m}$, sendo a mais espessa da bacia. A seqüência propriamente dita inicia-se com metarenitos feldspáticos a arcoseanos 


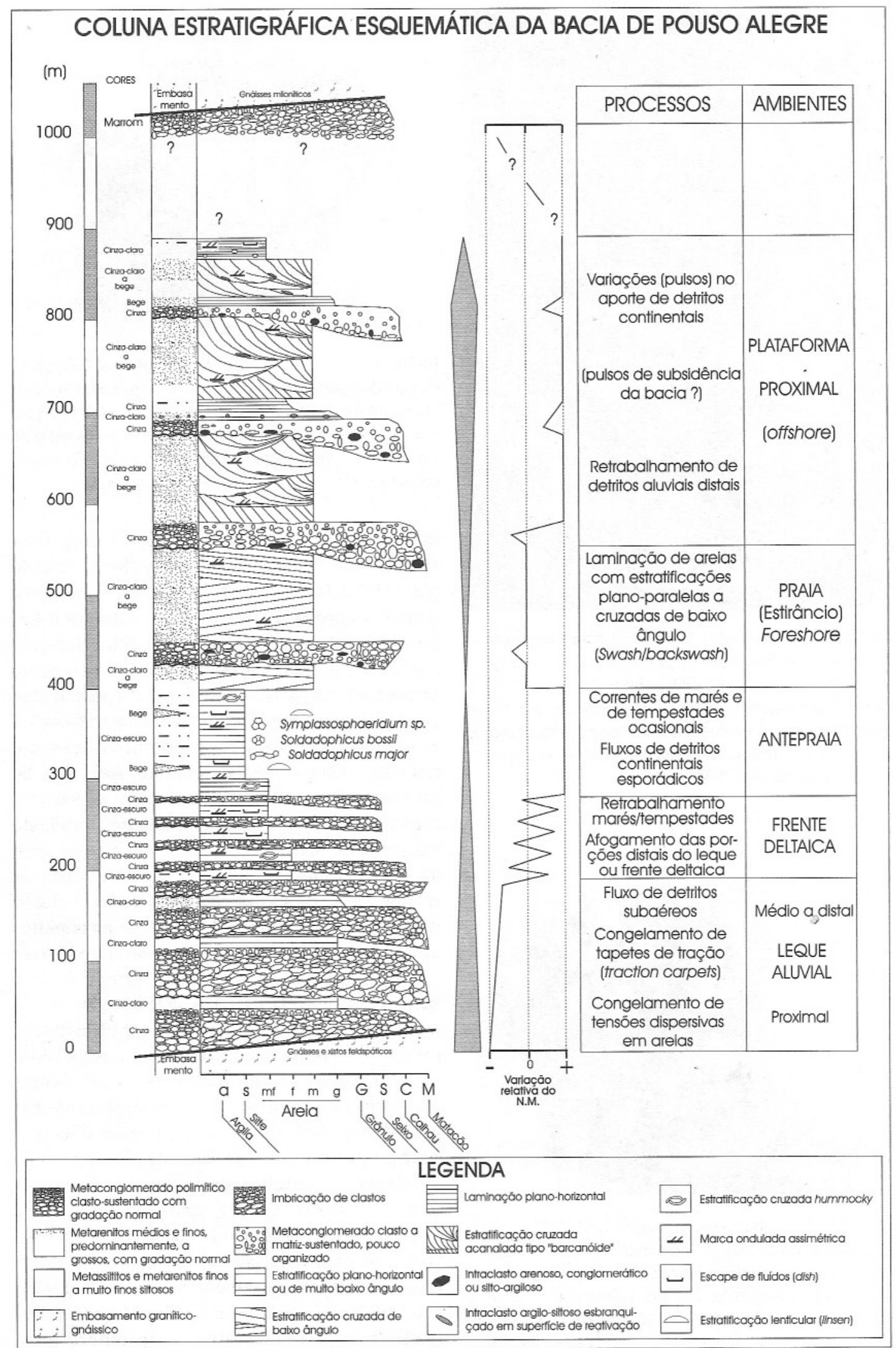

FIGURA 5 - Coluna estratigráfica esquemática composta da bacia de Pouso Alegre. 


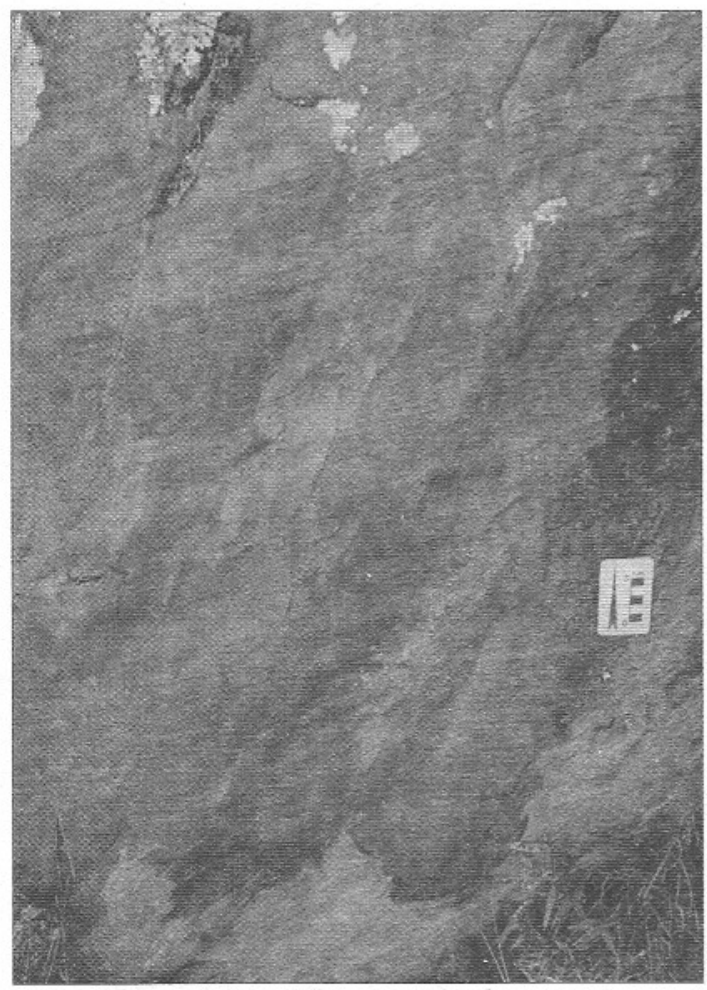

FIGURA 6 - Metarenitos muito finos com estratificação cruzada de pequeno porte, gradacionais ao topo para metassiltitos cinza e metargilitos cinza-escuro. Até a altura da escala predominam metapelitos. Acima desta ocorrem metarenitos, cujas lâminas frontais dos estratos cruzados atingem mergulhos ao redor de $30^{\circ}$. Fluxo da esquerda para a direita da foto (NW).

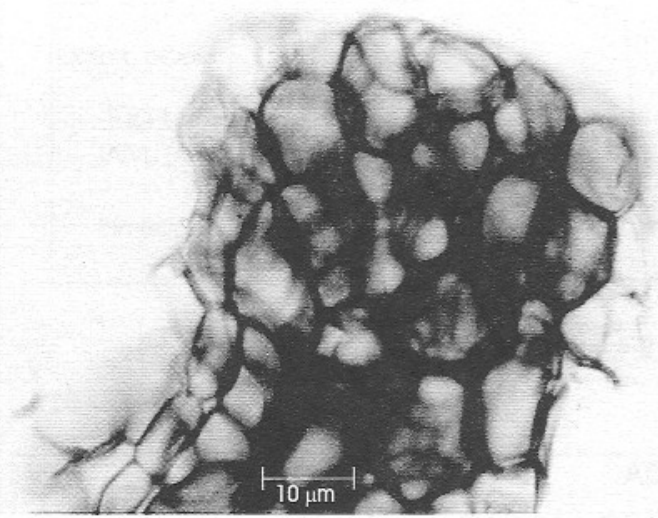

FIGURA 7 - Soldadophycus major GAUCHER 2000: Colônia de esferóides poligonizados pela compressão mútua, com desenvolvimento de indivíduos filamentosos cilíndricos, à esquerda da foto. Diâmetro médio dos esferóides $=9,5 \mu \mathrm{m}(7,5-12,5 \mu \mathrm{m}, \mathrm{N}=10)$. Amostra PA06, metassiltito calcífero da bacia de Pouso Alegre. Slide B (54.2, 105.2), filme 25 (33). Fotografia cedida por Claudio Gaucher e Peter Sprechmann.

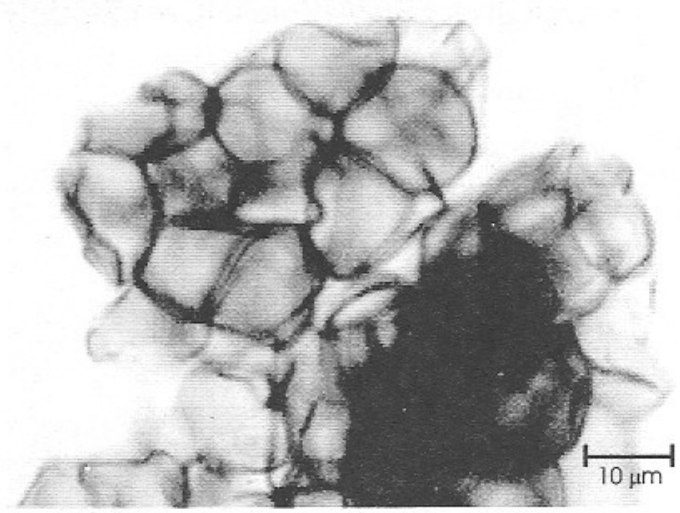

FIGURA 8 - Symplassosphaeridium sp. com colônia de esferóides poligonizados pela compressão mútua. Diâmetro médio dos esferóides de $9,8 \mu \mathrm{m}$ (7,5-11,3 $\mu \mathrm{m}$, $\mathrm{N}=8$ ). Amostra PA-06, metassiltito calcífero da bacia de Pouso Alegre. Slide B (26.0, 94.8), filme 25 (32). Fotografia cedida por Claudio Gaucher e Peter Sprechmann.

grossos a finos, laminados $(0,3-1 \mathrm{~cm})$, com estratificação cruzada de baixo ângulo e de grande porte (FIGURA 9) e com intercalações de lentes ricas em opacos. Para o topo, as estratificações assumem menor porte e passam a estratificações cruzadas planares e acanaladas, estas últimas de menor porte ainda. Neste nível, passa a predominar, gradativamente, metarenitos finos com ondulações assimétricas e cristas predominantemente retilíneas. Esta seqüência tem em média $4 \mathrm{~m}$ de espessura. Uma nova sequiência com as mesmas características pode suceder a anterior, erodindo em parte, ou não, suas porções de topo, ao longo da superfície de reativação. Freqüentemente, os termos arenosos são intercalados por associação de fácies de metaconglomerados e de metarenitos mal selecionados (traction carpets) com base geralmente plana, a localmente irregular, que literalmente cinzela a seqüência (FIGURA 10).Os metaconglomerados são polimíticos, predominantemente clasto-sustentados, com arcabouço constituído por clastos de mesma constituição daqueles metaconglomerados polimíticos da base da bacia, ressaltando-se o grande predomínio de clastos de milonitos (gnaisses e quartzitos milonitizados) sobre os demais. A matriz é lítica, arcoseana em geral, e apenas ocupa interstícios entre os clastos. Gradações normais são constantes, e não muito raro inversas, e ocorrem em intervalos de poucos centímetros a decímetros, passando os termos psefíticos a metarenitos conglomeráticos, metarenitos mal selecionados e, finalmente, a metarenitos finos a médios, com estratificações 


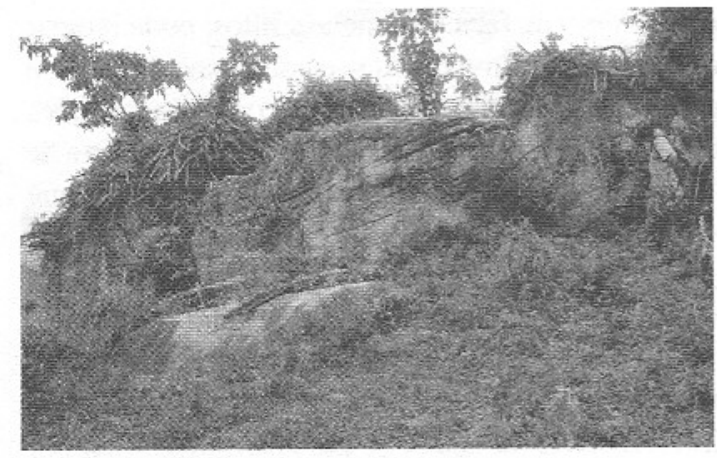

FIGURA 9 - Metarenitos médios a finos laminados com estratificação plano-horizontal a cruzada de baixo ângulo, associados a ambiente litorâneo de praia.

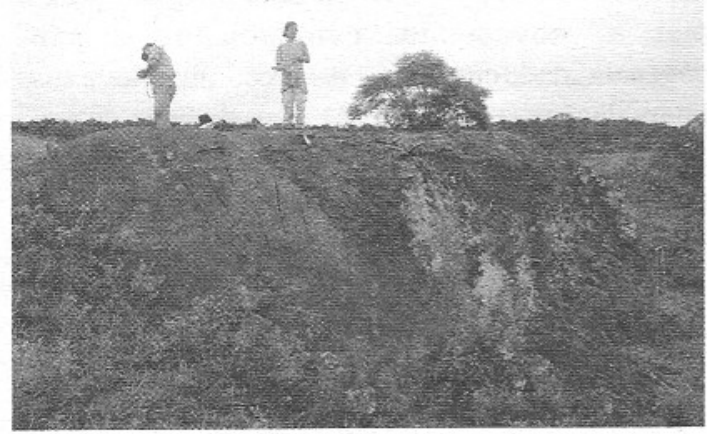

FIGURA 10 - Metarenitos médios a finos com estratificações cruzadas de baixo ângulo a acanaladas de grande porte, cinzelados por metaconglomerado polimítico clasto-sustentado, onde predominam clastos de milonitos.

cruzadas de baixo ângulo e cruzadas de pequeno a médio porte.

À medida que se avança para SE, mais para o topo da bacia, predomina associação de fácies de metarenitos laminados e mal selecionados, com grânulos e, localmente, com seixos intra e extraclásticos, com estratificação cruzada acanalada de grande porte (dunas barcanóides), estratificações cruzadas planares e acanaladas de pequeno porte (FIGURA 11). A gradação normal ocorre nas lâminas de metarenitos médios a finos e a gradação inversa pode ocorrer nas lâminas de metarenitos grossos com grânulos, associada a processos de fluxo de grãos (grain flow). A presença da associação de fácies de metaconglomerados polimíticos e metarenitos mal selecionados intercalados é uma constante. Difere da anterior quanto à maior participação dos termos arenosos em relação aos conglomeráticos e quanto ao predomínio de calhaus e seixos no arcabouço, mas,

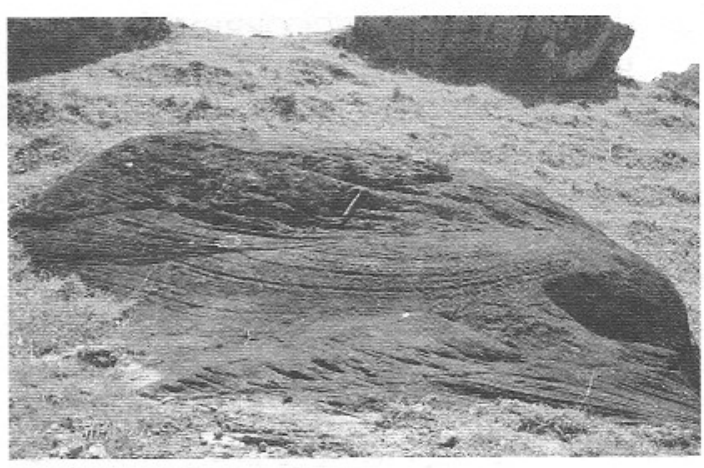

FIGURA 11 - Metarenitos médios a finos laminados com estratificações cruzadas acanaladas de médio a grande portes, definindo dunas do tipo barcanóide. Fluxo da esquerda para a direita da foto.

localmente, podem ocorrer matacões com mais de $1 \mathrm{~m}$ de tamanho.

No final da encosta, a sudeste, as exposições rochosas foram encobertas pelos depósitos aluviais recentes de várzea. Reaparecem, após o vale, apenas metaconglomerados polimíticos marrom amarelado, muitíssimo alterados, com seixos e calhaus de granitóides, quartzitos e milonitos, em contato tectônico com o embasamento granitóide, a sudeste.

\subsubsection{Interpretação}

Pequena regressão marinha instala-se com a deposição de extenso pacote de sedimentos praiais (metarenitos) intercalados por outros de proveniência continentais, representados por metaconglomerados polimíticos ricos em clastos de rochas miloníticas. De modo gradual, a seqüência anterior dá lugar à outra representativa de águas mais profundas, das regiões de antepraia (shoreface) a plataforma proximal (offshore), onde a ação de ondas normais e de correntes de marés construiu espetaculares megamarcas onduladas (dunas barcanóides) com fluxos voltados para o continente. Ainda assim, neste ambiente, as intercalações conglomeráticas mostraram-se constantes, evidenciando a continuidade das progradações deltaicas (fan-delta). No final da seqüência (FIGURA 5), aparentemente retornariam condições transgressivas, entretanto a ausência de exposições rochosas não permitiu confirmá-lo. Após esse intervalo sem exposições, no topo e borda sudeste da bacia (contato com o embasamento), expõem-se metaconglomerados polimíticos, que poderiam constituir-se em mais uma das intercalações aos depósitos arenosos ou representar estágio regressivo, com predomínio de fácies de metaconglomerados polimíticos. 


\section{ANÁLISE DAS PALEOCORRENTES E DA PALEOGEOGRAFIA DOS DEPÓSITOS}

Na unidade com predomínio de fácies de metaconglomerados polimíticos e de metarenitos mal selecionados, na base da bacia, o sentido aparente das paleocorrentes (relativo ao plano de corte; no caso, em planta) obtido a partir da imbricação de clastos nos tapetes de tração de leques aluviais subaéreos, indicaram fluxos de NE para SW, apontando área-fonte a NE (FIGURA 12). Nas intercalações de fácies metapelíticas a arenosas, que ocorrem a partir das porções médias dessa unidade, as ondulações assimétricas indicaram fluxos no sentido inverso, de SW para NE, comprovando a não cogeneticidade entre os termos predominantes e estes últimos. Interpreta-se que nas porções mais distais do leque aluvial subaéreo foi desenvolvida frente deltáica sujeita ao retrabalhamento por correntes de marés e ondas de tempestades, em águas relativamente rasas e próximas da linha de costa. A sequiência de fining e thickening-upward (FIGURA 5) que se instala a partir desses setores até o final da unidade, quando esta passa ao predomínio de fácies de metassiltitos, pode indicar retrogradação aluvial/deltáica com recuo da escarpa de falha. Ou, apenas indicar que ocorreram variações climáticas que implicaram na redução do aporte de detritos, o que parece pouco provável, uma vez que não há evidências de que o delta (fan-delta) passasse a ser controlado por correntes de marés ou mesmo de tempestades.

$\mathrm{Na}$ unidade de fácies com predomínio de metarenitos finos e metassiltitos calcíferos, intermediária da bacia, as paleocorrentes medidas em ondulações cavalgantes de metarritimitos siltoargilosos mostraram sentido dos fluxos de SW para $\mathrm{NE}$, ou seja, dirigidos para as áreas-fonte aluviais. Em suas intercalações de metarenitos conglomeráticos, as estratificações cruzadas de pequeno porte indicaram sentido das paleocorrentes inverso, de NE para SW, ou seja, dirigidas para o mar e, novamente, evidenciando a nãocogeneticidade entre as fácies predominantes e suas intercalações (FIGURA 12). Nas porções de topo dessa unidade, as paleocorrentes obtidas em ondulações cavalgantes subcríticas, em termos siltoargilo-arenosos, indicaram correntes dirigidas de $\mathrm{SE}$

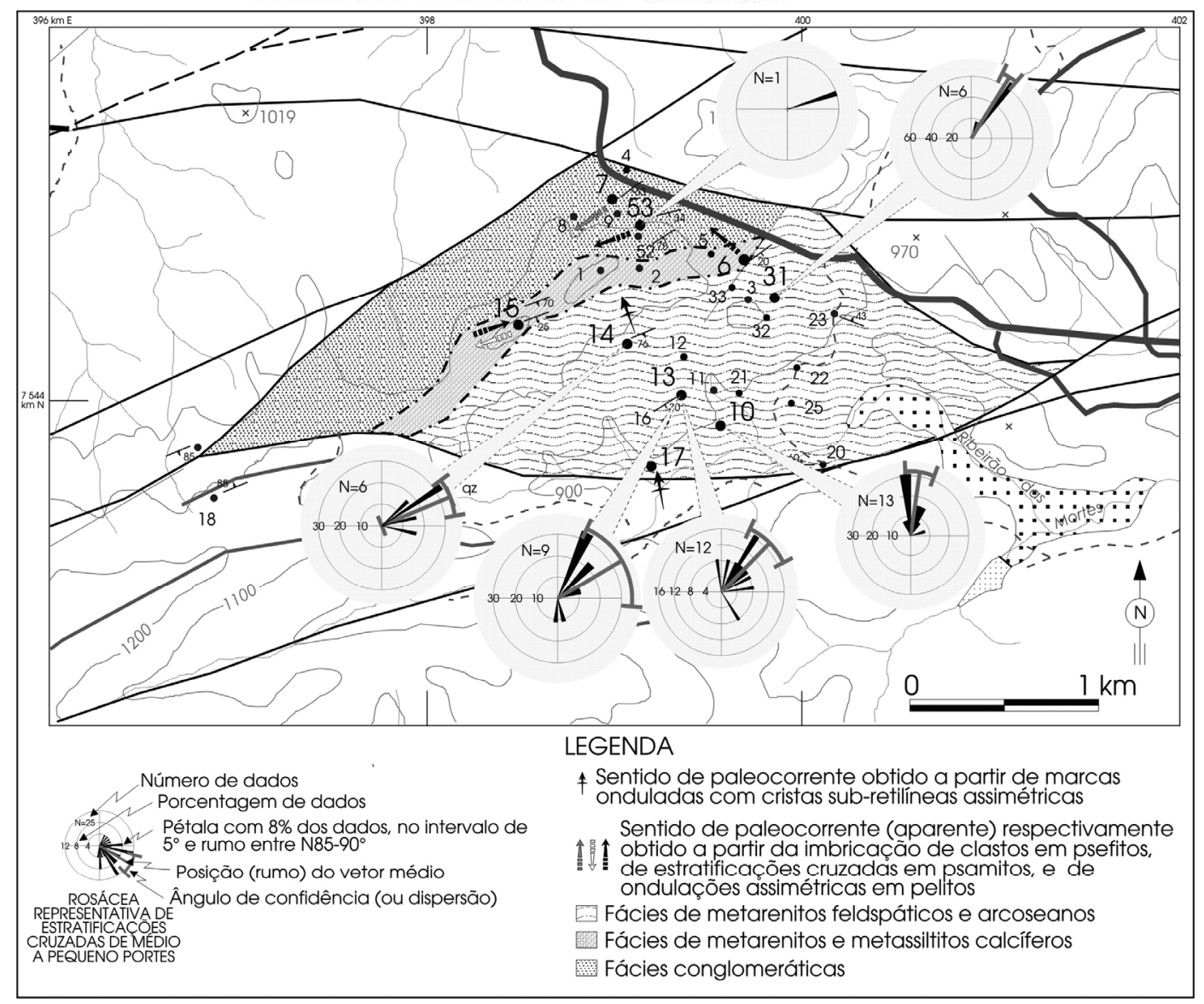

FIGURA 12 - Análise das paleocorrentes obtidas para a bacia de Pouso Alegre. 
para NW (plano de corte vertical, orientado segundo NW-SE). Nestas porções, as intercalações são cogenéticas e o sentido dos fluxos concordante, evidenciando a retrogradação máxima do sistema aluvial/deltaico, ou máximo transgressivo, e quietude tectônica no arcabouço da bacia. Aparentemente, essas condições não estiveram relacionadas a variações climáticas importantes, uma vez que a circulação das águas se manteve normal: incidência de correntes de marés e, ocasionalmente, de tempestades nas regiões de antepraia (shoreface)/ plataforma rasa(offshore). Nessas condições, parece ter havido uma expansão do perfil da praia, em especial da região de antepraia. As incursões deltaicas/aluviais, na base dessa unidade, restringiram-se a termos arenosos conglomeráticos com espessuras delgadas, o que evidenciaria a máxima retrogradação aluvial/deltaica (FIGURA 5), recuo máximo da escarpa e quietude tectônica, com a conseqüente modificação no caráter da construção deltáica, agora de granulometria mais fina (leque distal). Ou, de outro modo, inexistiriam as construções deltaicas e os fluxos continentais chegariam até as regiões de antepraia conduzidos por canais ou lobos, após serem retrabalhados nas regiões do pós-praia ou de estirâncio.

Na unidade superior, de predomínio de fácies de metarenitos feldspáticos e arcoseanos, as paleocorrentes foram obtidas principalmente nas porções intermediárias e de topo da unidade, em dunas barcanóides que, invariavelmente, mostraram fluxos de SW para NE, ou seja, dirigidas para o continente (FIGURA 12). Nas porções de topo dessas dunas e dos depósitos de praia (swash/ backswash) da base da unidade, as marcas onduladas assimétricas com cristas retilíneas, desenvolvidas sobre termos arenosos finos com espessuras delgadas, mostraram fluxos de SSE para NNW, também dirigidos para o continente, mas com pequeno desvio para NW em relação ao sentido nas dunas barcanóides.

Os depósitos de praia avançaram sobre os depósitos finos (shorefaceloffshore) da unidade intermediária de modo rápido, mas gradativo, caracterizando delgada seqüência de coarsening e thickening-upward, a par da variação negativa (regressão) do nível do mar. O perfil de praia encontrava-se ampliado, propiciando construções arenosas mais portentosas nas regiões de antepraia e do estirâncio (foreshore). Após somar algumas dezenas de metros os pacotes de areias praiais começam, em direção ao topo (FIGURA 5), a receber intercalações conglomeráticas nas quais se destaca a natureza destes como tapetes de tração (conglomerados/areias) e o grande predomínio de clastos miloníticos nos termos conglomeráticos. Essas evidências apontam reativação tectônica do arcabouço (área-fonte) com soerguimento e início de recuo da escarpa de falha (clastos miloníticos). As intercalações de fácies conglomeráticas persistem até as regiões de topo da unidade, limites com o embasamento, podendo-se notar que, paulatinamente, da base para o topo, a relação conglomerados/areia é diminuída, diferenciando esses tapetes de tração, desenvolvidos em ambiente subaquoso, daqueles da base da bacia, desenvolvidos em ambiente subaéreo e associados a leques aluviais. Localmente, estratificações cruzadas acanaladas de pequeno porte em termos arenosos de tapetes de tração subaquosos mostraram paleocorrentes dirigidas de NE para SW. Conclui-se pois que os depósitos eminentemente arenosos não guardam cogeneticidade com aqueles eminentemente conglomeráticos. Estes últimos atingiram as regiões de antepraia e de plataforma proximal, onde se desenvolviam as ondas de areias, de modo desconfinado, não havendo evidências de canais, mas sim de superfícies erosivas planas, na base e topo destes. Tais evidências podem apontar o reinício das construções deltaicas (fandelta) em decorrência da reativação tectônica na área-fonte, a par da variação negativa do nível do mar devido às variações eustáticas do oceano ou, talvez menos provável, devido apenas à progradação deltáica/aluvial.

Finalmente, é possível concluir que a deposição ocorreu sob forte influência da tectônica que disponibilizou em regiões de escarpa de falhas, relativamente próximas da linha de costa, leques aluviais que avançaram até as regiões de plataforma proximal na forma de deltas de granulação grossa. A calmaria tectônica teve curta duração, permitindo a deposição de delgado pacote de termos metapelíticos sujeitos ao retrabalhamento de ondas normais e de tempestades, marcando o máximo transgressivo na bacia. Possível regressão se inicia com a sobreposição gradativa dos depósitos de praia com relação àqueles de antepraia/plataforma rasa, evidenciando variações eustáticas do oceano ou prenunciando apenas a chegada das frentes deltaicas, em decorrência da reativação tectônica e da progradação aluvial.

\section{GEOLOGIA ESTRUTURAL}

Na bacia de Pouso Alegre o acamamento reliquiar $\left(\mathrm{S}_{0}\right)$ guarda boa concordância estrutural 
com o trend principal do embasamento, assumindo atitude média de $\mathrm{N} 55^{\circ} \mathrm{E} 39^{\circ} \mathrm{SE}$. Ele é interceptado por uma clivagem ardosiana $\left(\mathrm{S}_{1}\right)$ com atitude média de $\mathrm{N} 65^{\circ} \mathrm{E} 64^{\circ} \mathrm{SE}$, podendo-se notar que as direções

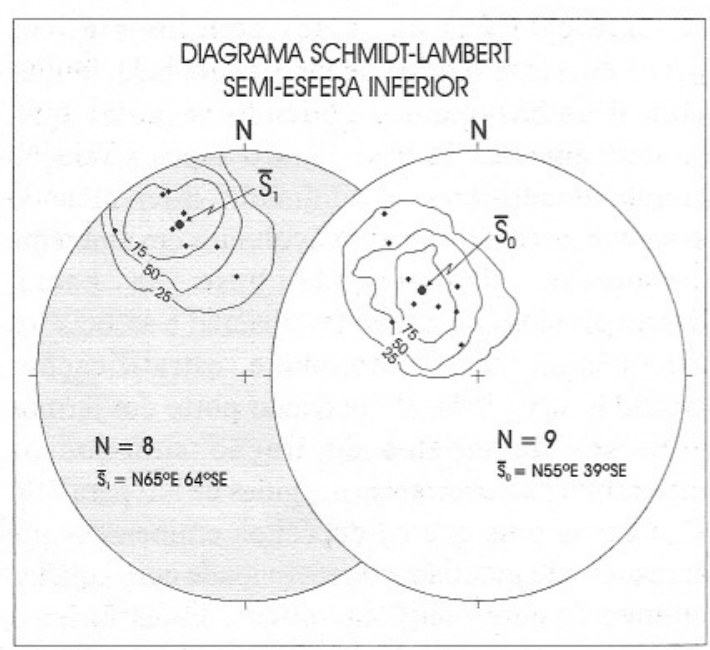

FIGURA 13 - Diagrama de igual área para as projeções polares do acamamento $\left(\mathrm{S}_{0}\right)$ e da clivagem ardosiana $\left(\mathrm{S}_{1}\right)$ medidos na bacia de Pouso Alegre. $\overline{\mathrm{S}}_{0}$ e $\overline{\mathrm{S}}_{1}$ são, respectivamente, as atitudes médias do acamamento e da foliação metamórfica.

são sub-paralelas às de $\mathrm{S}_{0}$, mas que os mergulhos, para o mesmo quadrante, são de maior ângulo (FIGURA 13).

O formato aproximadamente triangular isósceles a trapezoidal da bacia, aliado à rede de falhas que a limita, é sugestivo de que as últimas deformações sofridas por ela foram impressas por binário de esforços sinistral; entretanto, não foram diagnosticadas evidências contundentes que o comprovassem. Em alguns locais, nos metaconglomerados polimíticos da unidade basal a NW, rotações de clastos foram sugestivas de movimentação sinistral, mas nestes mesmos locais, ao lado de tais clastos, outros mostravam o predomínio de rotações sugestivas de deformações associadas a binários destrais.

Nos metaconglomerados com intercalações de metarenitos e metassiltitos, planos de falhas com mergulhos de $60^{\circ}$ para NW provocaram rejeitos inversos de até $40 \mathrm{~cm}$ nas intercalações metapelíticas/psamíticas, porém, devido à ausência de estrias nos planos de fraturas, não foi possível caracterizar a componente horizontal. Nos metassiltitos calcíferos, a clivagem ardosiana $\left(\mathrm{S}_{1}\right)$ intercepta com direção sub-paralela $\left(\mathrm{N} 70^{\circ} \mathrm{E} 70^{\circ} \mathrm{SE}\right)$ 0 acamamento reliquiar $\left(\mathrm{S}_{0}\right)$ de baixo ângulo de mergulho $\left(25^{\circ}\right.$ para sul), relação indicativa de vergência para NW. Exames mesoscópicos e microscópicos mostraram que $\mathrm{S}_{1}$ comporta-se como uma clivagem de cisalhamento (microfraturas) que provoca rejeitos normais milimétricos (até $0,5 \mathrm{~cm}$ ) em $\mathrm{S}_{0}$, situando-se a lapa a sul e a capa a norte. A componente horizontal não foi possível de ser estabelecida em campo e mesmo a análise de seção delgada orientada também não mostrou sucesso.

Nas rochas do embasamento situadas meridionalmente à bacia (FIGURA 2) e com melhores exposições rochosas que as demais áreas do embasamento de entorno, as observações tiveram mais sucesso. No extremo WSW da bacia afloram gnaisses facoidais a blastomiloníticos com intercalações de quartzitos, cortados por planos de falhas rúptil-dúcteis com atitude $\mathrm{N} 68^{\circ} \mathrm{E} 85^{\circ} \mathrm{SE}$. Os espelhos de falha contêm estrias de atrito suborizontais $\left(3-12^{\circ} \mathrm{W}\right)$. As demais feições cinemáticas dos espelhos (como degraus), associadas ao estriamento, forneceram indicações de movimentação lateral direita com pequena componente normal (plano de muito alto ângulo de caimento), que poderia ser extensiva para toda a falha que limita o embasamento com os metaconglomerados polimíticos da base da bacia. Nos quartzitos, situados a poucas dezenas de metros a sudeste da exposição anterior, as mesmas relações foram observadas em plano principal de cisalhamento com atitude $\mathrm{N} 68^{\circ} \mathrm{E} 85^{\circ} \mathrm{NW}$ (alto ângulo de mergulho, mas para o quadrante NW). As estrias de atrito horizontais $\left(0^{\circ}\right)$ foram superpostas por outras subverticais, indicativas de falha normal, situando-se o bloco alto a sul. Mais a noroeste, planos de falhas com alto ângulo de mergulho para NW $\left(75^{\circ}\right)$ e estrias de atrito suborizontais $\left(14^{\circ} \mathrm{W}\right)$ interceptam gnaisses facoidais, com feições indicativas de movimentação lateral direita e componente inversa. E, finalmente, pouco mais a noroeste e ainda em rochas gnaissicas, planos de falhas $\left(\mathrm{N} 66^{\circ} \mathrm{E} 85^{\circ} \mathrm{NW}\right)$ com estrias suborizontais $\left(10^{\circ}\right.$ W) e as demais feições do espelho indicaram movimentação lateral direita com componente inversa, com sobreposições no plano principal e em planos simétricos (com caimento para sul) de rejeitos normais. Reconhecendo-se a escassez dos dados estruturais obtidos nos depósitos de Pouso Alegre e no seu embasamento, mas, considerada a boa qualidade destes, é possível atribuir que a deformação principal imposta à bacia, durante a sua fase de inversão e encurtamento, obedeceu a um binário de esforços com vetores máximos compressivos orientados aproximadamente segundo E-W, provocando na rede de cisalhamentos preexistente e em novas geradas uma 
movimentação oblíqua, predominantemente lateral direita com componente inversa.

\section{CORRELAÇÃO DA BACIA DE POUSO ALEGRE COM OUTRAS BACIAS DA TRANSIÇÃO NEOPROTEROZÓICO- CAMBRIANO}

Dada a proximidade geográfica e o contexto geológico semelhante, a correlação mais direta dos depósitos de Pouso Alegre seria com aqueles de Eleutério, situados no extremo WSW do corredor estreito formado pelos terrenos do Cinturão Alto Rio Grande, entre Jacutinga (MG) e Itapira (SP). Os depósitos de Eleutério foram descritos por EBERT (1968 e 1971) e constituíram, também, objeto de análise para vários autores, entre eles CAMPANHA et al. (1982), ZANARDO (1987)e TEIXEIRA (1995). TEIXEIRA (2000) retomou os estudos na bacia de Eleutério utilizando-se de métodos e técnicas multidisciplinares, cujos resultados parciais serão incorporados no decorrer da argumentação que se seguirá.

De acordo com os levantamentos geológicos realizados no sul de Minas Gerais e nordeste de São Paulo por vários autores (como SOARES 1976, CAMPANHA et al. 1982, ZANARDO 1987, VASCONCELLOS 1988, e TEIXEIRA 1995), entre as bacias de Pouso Alegre e de Eleutério ocorre uma série de manchas de sedimentos isoladas dos corpos principais dessas bacias, que sugerem ter havido entre elas uma continuidade física pretérita ou, pelo menos, uma contigüidade (FIGURA 14). Entretanto, até o momento, não se identificou qualquer horizonte-guia comum às duas bacias, em que pesem as similaridades no estilo deposicional e no ambiente tectônico existente entre elas (TEIXEIRA 2000).

Com relação às demais bacias, excetuandose a de Cajamar, o estilo deposicional e os ambientes tectônicos de evolução guardam similaridades entre si e com a bacia de Pouso Alegre: no continente, áreas-fonte escarpadas com leques aluviais com eventual planície aluvial com rios entrelaçados nas porções distais; em ambientes transicionais, fandelta ou braided-delta, ambientes estuarinos/ planície de marés ou até de plataforma proximal rasa (offshore); e, quanto à tectônica, o controle efetivo na sedimentação com a geração de depósitos imaturos e intensamente retrabalhados (canibalismo), evidenciam a alta energia nos processos; por fim, a fase de inversão e encurtamento de todas elas situada no limite máximo de 530 Ma(HAMA \& CUNHA 1977, TEIXEIRA 1995 e TEIXEIRA 2000). Como limite máximo para o início da sedimentação, baseando-se na presença de clastos de rochas granitóides de arcos magmáticos com idades absolutas bem estabelecidas, pode-se invocar uma idade ao redor de $600 \mathrm{Ma}$.

A bacia de Cajamar (HACHIRO \& SANTORO 1996 e TEIXEIRA 2000) provavelmente constitui resto de uma plataforma carbonática, cuja dimensão original deveria ser muito maior, dado à disponibilidade de áreas para o desenvolvimento de margens passivas com deposição carbonática nas porções ocidentais a meridionais do Cráton do Paraná. Com depósitos característicos de.plataforma rasa e águas oxigenadas, HACHIRO \& SANTORO (1996) reportaram na bacia de Cajamar a ocorrência de clastos fosfáticos em delgada seqüência de metaconglomerados no topo da unidade, evidenciando a ocorrência de fenômenos de ressurgência oceânica, característicos de conexões oceânicas amplas em estágios pós-glaciais, como registrado no Grupo Corumbá (BOGGIANI 1998).

Quanto ao conteúdo fossilífero, nos depósitos intermediários na bacia de Pouso Alegre (fácies de metassiltitos calcíferos), de acordo com TEIXEIRA (2000), ocorrem os acritarcos Symplassosphaeridium sp. e Soldadophicus major GAUCHER (2000) e também Soldadophycus bossii GAUCHER et al. 1996, recentemente reportado por TEIXEIRA \& GAUCHER (2001). Na bacia de Eleutério foram identificados os microfósseis Cloudina cf. C. riemkeae GERMS (1972), Titanotheca coimbrae GAUCHER \& SPRECHMANN 1999 (TEIXEIRA 2000) e Bavlinella faveolata (SCHEPELEVA) VIDAL (TEIXEIRA \& GAUCHER 2001), associados aos pacotes de metalaminitos da base da bacia. Nos depósitos heterolíticos do Pico de Itapeva foram descritos os microfósseis Titanotheca coimbrae e Bavlinella faveolata (TEIXEIRA \& GAUCHER 2001). E, finalmente, nos depósitos de Cajamar, TEIXEIRA (2000) reportou a ocorrência de Titanotheca coimbrae GAUCHER \& SPRECHMANN 1999.

Esta associação fossilífera permite correlacionar os depósitos de Pouso Alegre e outros similares que ocorrem ao longo do Cinturão Ribeira, entre Minas Gerais e o Paraná, com os grupos Corumbá, no Mato Grosso do Sul, Arroyo del Soldado, no Uruguai, e Nama, na Namíbia, que tiveram suas porções inferiores a médias situadas no Vendiano Superior a partir de datações por métodos isotópicos, bio- e quimioestratigráficos (GERMS 1995, BOGGIANI 1998 e GAUCHER 2000, entre outros). 


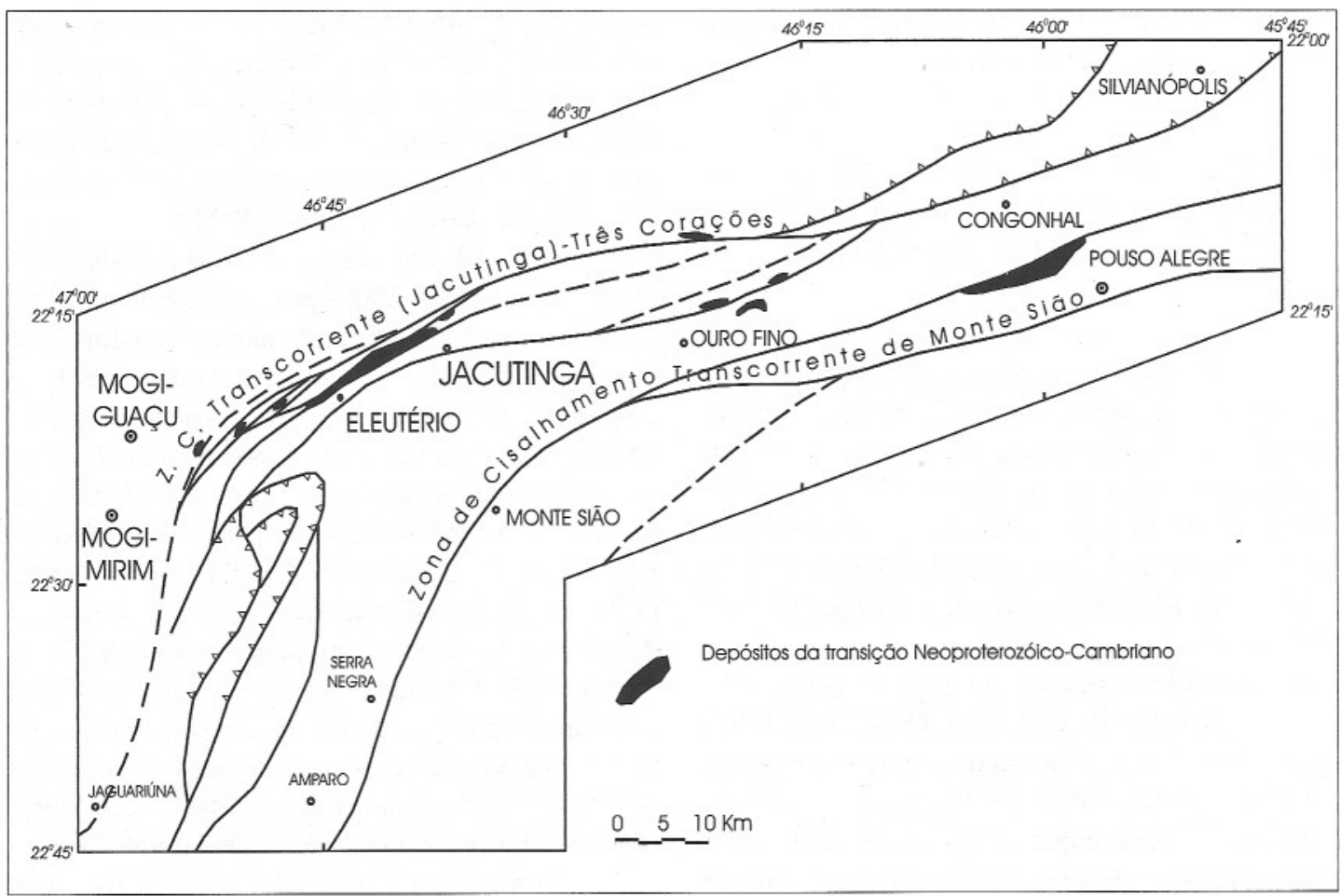

FIGURA 14 - As bacias de Eleutério e de Pouso Alegre e as ocorrências menores relacionadas aos depósitos da transição Neoproterozóico-Cambriano, com distribuição geográfica sugestiva de uma continuidade ou, pelo menos, uma contigüidade pretérita entre essas bacias (Compilado e modificado de SOARES 1976, CAVALCANTE et al. 1979, CAMPANHA et al. 1982 e TEIXEIRA 1995).

O Grupo Corumbá ocorre desde os arredores do Maciço do Urucum, no norte do Estado do Mato Grosso do Sul, até as porções de sudeste da Serra da Bodoquena, nos limites desse estado com o Paraguai. Seus depósitos ocupam a porção oriental do Cráton Amazônico, recobrindo-o ou associados ao Cinturão de Dobramentos Paraguai, onde se encontram dobrados. De acordo com BOGGIANI (1998), o Grupo Corumbá é constituído por um pacote com cerca de $700 \mathrm{~m}$ de espessura, que apresenta na base arenitos e pelitos das formações Cadiueus e Cerradinho passando ao topo para dolomitos da Formação Bocaina, calcários e pelitos carbonosos da Formação Tamengo que, ao final, são recobertos por pelitos da Formação Guaicurus. Estratigraficamente, o Grupo Corumbá estaria situado sobre as unidades do Grupo Cuiabá, sobrepondo-se aos depósitos glácio-marinhos da Formação Puga, e sotoposto às unidades continentais terrígenas do Grupo Alto Paraguai (BOGGIANI 1998). Este autor, em função das características sedimentares, quimio- e bioestratigráficas, correlacionou o Grupo Corumbá às demais unidades mundiais pós-glaciação varangeriana, caracterizando para esta um embaciamento do tipo rift-to-drift associado com as interações interplacas suscitadas pela fragmentação do Supercontinente Pannotia, durante o Neoproterozóico. À fase rift, BOGGIANI (1998) relacionou a sedimentação continental das formações Cadiueus e Cerradinho e os depósitos dolomíticos e ricos em construções estromatolíticas da Formação Bocaina que se sucederam, ocupando ampla superfície de aplainamento em margem passiva do tipo Atlântico, propensa à intensa circulação oceânica e a eventos fosfogenéticos. Nos siltitos esverdeados da Formação Cerradinho GAUCHER (2000) reportou a abundância da cianobactéria Bavlinella faveolata, concluindo que além das semelhanças litoestratigráficas que esses siltitos desfrutam com com aqueles da Formação Yerbal, da base do Grupo Arroyo del Soldado, existem também aquelas fossilíferas. À fase drift, BOGGIANI (1998) relacionou o rebaixamento eustático do nível do mar, que implicou na ressedimentação na borda do talude dos depósitos da Formação Bocaina. Acompanhando uma transgressão marinha ocorreu a deposição dos calcários calcíticos da Formação Tamengo, cuja deposição em águas rasas foi propícia ao desenvolvimento da vida metazoária, principalmente representada pelo microfóssil Cloudina lucianoi (ZAINE \& FAIRCHILD 1985 e 
ZAINE 1991) e o megafóssil ediacariano Corumbella werneri (WALDE et al. 1982), e à geração de níveis fosfogenéticos (microfosforitos). A sedimentação carbonática foi interrompida com a brusca variação climática e o topo da bacia foi preenchido por folhelhos da Formação Guaicurus, encerrando o Grupo Corumbá. Baseando-se em comparações do conteúdo paleontológico e do comportamento dos isótopos de $\mathrm{C}, \mathrm{O}$ e $\mathrm{Sr}$ com os padrões apresentados pelo Grupo Nama (Namíbia), BOGGIANI (1998) estimou que a sedimentação na Formação Tamengo teria ocorrido entre 548-544 Ma. O autor, finalmente, considerou as possibilidades de correlações entre o Grupo Corumbá e os grupos la Tinta, na Argentina, e Arroyo del Soldado, no Uruguai.

O Grupo Arroyo del Soldado foi definido por GAUCHER et al. (1996) na porção centro-sul do Uruguai. Seus depósitos assentam-se com discordância angular e erosiva exclusivamente sobre o Terreno Nico Pérez, porção arqueana do Cráton Rio de la Plata retrabalhada pelos processos tectono-termais neoproterozóico-cambrianos (BASEI et al. 2000). De acordo com GAUCHER \& SPRECHMANN (1999) e com GAUCHER (2000) o pacote deposicional supera $5000 \mathrm{~m}$ de espessura. Os autores registraram nos depósitos três transgressões e regressões que se sucederam no tempo. A sedimentação teve início no Vendiano Superior (Kotlinian), com a deposição terrígena da Formação Yerbal em uma plataforma continental estável, do tipo Atlântico, sob influência de transgressão marinha que se seguiu à deglaciação Varangeriana. Superiormente a esta unidade seguiram-se os depósitos associados à primeira fase regressiva, representados pelas formações Polanco (carbonatos) e Barriga Negra (conglomerados e arenitos). Com nova transgressão são depositados pelitos, BIF e cherts da Formação Cerro Espuelitas, quando novo evento regressivo, marcado por conspícua superfície erosiva, propicia a deposição de arenitos basais da Formação Cerros San Francisco, provavelmente no limite do Neoproterozóico-Cambriano. Retomando-se condições transgressivas, com a deposição predominantemente de siltitos, uma sensível mudança climática, para condições tropicais, propicia a deposição carbonática representada pela Formação Cerro Victoria. Nesta unidade de topo da bacia, os autores identificaram icnofósseis característicos do Cambriano Inferior associados com construções estromatolíticas. Além da vasta gama de microfósseis descrita pelos autores, como Cloudina riemkeae, Titanotheca coimbrae, Bavlinella faveolata, destaca-se nos depósitos do
Grupo Arroyo del Soldado a presença dos acritarcos Symplassosphaeridium sp., Soldadophicus major e Soldadophycus bossii, que também ocorrem na bacia de Pouso Alegre. GAUCHER \& SPRECHMANN(1999) e GAUCHER (2000) situaram a maior parte dos depósitos no Vendiano Superior. De acordo com GAUCHER (2000), a inversão da bacia implicou em amplos dobramentos acompanhados de metamorfismo brando dos depósitos durante o Cambriano Inferior, quando a plataforma do Arroyo del Soldado colidiu com o Cinturão Cuchilla Dionisio, correspondente do Cinturão Dom Feliciano, no sul do Brasil. GAUCHER \& SPRECHMANN (1999) e GAUCHER (2000) correlacionaram os depósitos do Grupo Arroyo del Soldado com aqueles dos grupos Corumbá e Jacadigo, do Brasil, e com os depósitos do Grupo Nama, da Namíbia, e também com outras unidades do Paraguai e Europa, baseando-se nas características estratigráficas e, principalmente, bioestratigráficas.

O Grupo Nama ocorre na porção ocidental do Cráton do Kalahari, aflorando a maior parte de seus depósitos em território da Namíbia. Pequena parte de depósitos contemporâneos a estes, que se encontram em território da África do Sul, foram englobados no Grupo Vanrhynsdorp. Os estudos estratigráficos nesse grupo tiveram início em 1912, com P. Range (GERMS 1974) e, desde então, inúmeros métodos e técnicas analíticas foram incorporados à análise de suas rochas. Da base para o topo o Grupo Nama é constituído pelos subgrupos Kuibis, Schwarzrand e Fish River, que somam mais de $3000 \mathrm{~m}$ de espessura. Nesta sucessão estão representados depósitos de ambientes marinhos rasos siliciclásticos e carbonáticos (GERMS 1995 e NARBONNE et al. 1997), que preencheram bacia de foreland, desenvolvida durante a interação convergente dos crátons do Congo, Kalahari e Rio de la Plata, aproximadamente entre $570-530 \mathrm{Ma}$ (GERMS 1995), concomitante ao fechamento do Oceano Adamastor (HARTNADY et al. 1985). Devido ao seu conteúdo fossilífero, o Grupo Nama tem se destacado como uma das unidades estratigráficas mais estudadas do mundo, principalmente no que concerne ao interesse dos estudiosos em determinar os processos geológicos e biológicos que marcaram a passagem Neoproterozóico-Cambriano, ou mesmo de precisar o intervalo de idades para esses processos. Os fósseis esqueletais, como Cloudina riemkeae, e outros microfósseis ocorrem nos depósitos do Grupo Nama ao lado de uma das mais expressivas faunas ediacarianas do mundo. A ocorrência de 
tufos vulcânicos nas porções superiores do Subgrupo Schwarzrand (unidade média do Grupo Nama) possibilitou a GROTZINGER et al. 1995, através de datações absolutas U-Pb de zircões, obter uma idade mínima de 543 Ma para os megafósseis ediacarianos, idade esta concordante com aquelas aferidas por BROWRING et al. 1993 para os limites do Proterozoico-Cambriano na Sibéria.

O microfóssil Cloudina, que ocorre na bacia de Eleutério e nos grupos Corumbá, Arroyo del Soldado e Nama, constitui importante referencial cronoestratigráfico, mundialmente reconhecido. Foi descrito pioneiramente no Grupo Nama, na Namíbia, por GERMS (1972) em rochas carbonáticas do Subgrupo Kuibis, basal, e do Subgrupo Schwarzrand, imediatamente superior. O seu intervalo de existência foi determinado por KNOLL (1996) entre 565-543 Ma, a partir de correlações estratigráficas e de datações absolutas pelo método $\mathrm{U} / \mathrm{Pb}$ de zircões de rochas piroclásticas intercaladas aos depósitos neoproterozóicos de vários continentes do mundo, onde o microfóssil ocorre. Foi também descrito em rochas carbonáticas do Grupo Corumbá por ZAINE \& FAIRCHILD (1985) e ZAINE (1991) e em metassiltitos da Formação Yerbal, unidade basal do Grupo Arroyo del Soldado (GAUCHER \& SPRECHMANN 1999 e GAUCHER 2000).

A ocorrência de Cloudina em metalaminitos da base da bacia de Eleutério (TEIXEIRA 2000), além de outros microfósseis relatados, torna bastante plausível o estabelecimento de correlações das bacias em questão, que ocorrem ao longo do Cinturão Ribeira, com as bacias do Corumbá, Arroyo del Soldado e Nama. Consideradas as similaridades entre as assembléias fossilíferas presentes e a suas associações com águas rasas, que se instalaram nas porções peri- e epicontinentais após o evento glacial Varanger, invoca-se que o preenchimento das bacias de Pouso Alegre e similares do Cinturão Ribeira também ocorreu principalmente durante o Vendiano Superior. Uma vez que os registros fossiliferos estão restritos às porções basais ou médias dessas unidades, é possível que a sedimentação tenha alcançado, a exemplo do que ocorre em outras situadas na América do Sul e África, o Cambriano Inferior.

De acordo com as considerações levantadas, assume-se que a sedimentação nas bacias de Pouso Alegre e nas demais bacias similares do Cinturão Ribeira ocorreu ao redor de 570-540 Ma, intervalo este principalmente referenciado na ocorrência de Cloudina riemkeae na bacia de Eleutério e nas correlações estratigráficas acima discutidas. Esse intervalo é compatível com aquele proposto para o final dos eventos magmáticos brasilianos, ocorridos ao redor de $580 \mathrm{Ma}$ (Cinturão Itu, VLACH et al. 1990) e, por outro lado, com as assinaturas isotópicas $\mathrm{K}-\mathrm{Ar}$ do embasamento regional e dos metassedimentos das bacias de Pouso Alegre e Eleutério, que mostram resfriamentos ocorridos ao redor de $530 \mathrm{Ma}$, ou seja, após a inversão e encurtamento dessas bacias (e.g. HAMA \& CUNHA 1977, TEIXEIRA 1995, SANTORO 1998, e SANTORO \& SILVA 1999, entre outros).

\section{CONSIDERAÇÕES PALEOGEOGRÁFICAS SOBRE A EVOLUÇÃODA BACIA DE POUSO ALEGRENOCONTEXTODO GONDWANA OCIDENTAL}

Os depósitos de Pouso Alegre e outros similares que ocorrem desde o sul de Minas Gerais até o Paraná tiveram sua gênese e evolução intrinsecamente relacionadas aos processos de convergência crustal que marcaram a consolidação do Gondwana Ocidental.

Com fragmentação e dispersão ( $c a$. 750-700 Ma) do Supercontinente Rodínia (MCMENAMIN \& MCMENAMIN 1990), que havia se aglutinado ao redor de $1 \mathrm{Ga}$, houve uma tendência para que uma série de blocos crustais, incluindo núcleos cratônicos, se aglutinasse em posições próximas do pólo sul, configurando o Supercontinente Pannotia (do grego, pan $=$ todos e notios $=$ ao sul), que de acordo com a concepção de POWELL (1995) teve duração efêmera e à qual se associou a glaciação Varanger (MEERT \& VAN DER VOO 1994). A fragmentação do Pannotia ao redor de $600 \mathrm{Ma}$ foi acompanhada de novas interações entre blocos crustais que mais tarde vieram configurar o Gondwana Ocidental. Entre os núcleos cratônicos envolvidos nessas interações destacam-se os do São Francisco, Rio de la Plata/Paraná, Amazonas/ Pampeano, Congo e do Kalahari, que são de maior interesse a este trabalho.

Considerando-se que os depósitos de Pouso Alegre exibem clastos provenientes tanto das rochas do embasamento mais antigo (Cinturão Alto Rio Grande, HASUI 1982) quanto de arcos magmáticos mais jovens (granitos e granitóides) e considerandose o conteúdo fossilífero e as correlações bioestratigráficas e tectono-estruturais com outros depósitos similares, invoca-se que a deposição nesta bacia ocorreu quando já haviam encerrado os processos de acrescentamento crustal com 
orogenia nestas porções ocidentais do Cinturão Ribeira(HASUI 1982).

De acordo com as proposições paleotectônicas e paleogeográficas de BRITO NEVES et al. (1999) e CAMPOS NETO (2000), previamente, ao redor de $630 \mathrm{Ma}$, os processos de colagem tectônica entre os crátons do São Francisco e do Rio de la Plata/Paraná encontravam-se finalizados com a Orogenia Tocantins (ALMEIDA et al. 1981), que resultou em complexo empilhamento de terrenos alóctones sobre as rochas que compõem o Cinturão Alto Rio Grande e sobre a borda sul do Cráton do São Francisco e no conseqüente fechamento do Oceano Goianides (PIMENTEL et al. 1997). Desse modo, uma extensa borda continental foi disponibilizada com a aglutinação dos crátons do São Francisco e do Rio de la Plata/ Paraná, cujo lado oriental voltava-se para o Oceano Adamastor (HARTNADY et al. 1985). Este oceano, aberto para o sul entre os referidos crátons e aqueles orientais do Congo e Kalahari, encontrava-se em paulatino processo de fechamento iniciado nos finais da Orogenia Tocantins e que só estaria finalizado ao redor de $490 \mathrm{Ma}$ (BRITO NEVES et al. 1999, SCHMITT et al. 1999 e CAMPOS NETO 2000) com a total consumação da bacia Adamastor e a consolidação final (cratonização) do Gondwana Ocidental.

Em função da subducção, de leste para oeste, envolvida no processo de fechamento do Oceano Adamastor, os processos orogenéticos e de colagem tectônica se concentraram na extensa borda oriental dos crátons do São Francisco/Rio de la Plata/Paraná, configurando-se o Orógeno Mantiqueira (CAMPOS NETO \& FIGUEIREDO 1995). A localização preferencial desses processos nessas bordas reflete na concentração de cerca de $95 \%$ das rochas granitóides, associadas aos arcos magmáticos, que atualmente se encontram do lado sul-americano (PORADA 1979).

Dado que a colagem tectônica envolvida foi diacrônica e envolveu a docagem de vários terrenos que se encontravam dispersos ao longo do oceano, grosso modo, os arcos magmáticos e demais terrenos amalgamados mais antigos situavam-se nas porções ocidentais do orógeno, onde as condições de estabilização com resfriamento crustal tiveram início mais cedo. Provavelmente também, no contexto de um novo equilíbrio que se estabelecia, os processos de convergência tangencial foram se esmaecendo e, paulatinamente, cederam lugar a outros de convergência lateral oblíqua que possibilitaram a geração de horts e grabens e, conseqüentemente, de sítios deposicionais no interior continental.
Nos finais da glaciação Varanger (MEERT \& VAN DER VOO 1994), que perdurou entre 625-580 $\mathrm{Ma}$, as condições gerais no planeta eram de ascensão das temperaturas e do nível dos oceanos e amplos espaços epi- e pericontinentais foram gerados para a sedimentação. Nas regiões subsidentes do Cinturão Ribeira, em gestação, as águas marinhas penetraram e vieram constituir nível de base para o preenchimento de bacias extensionais de contexto transcorrente (strike-slip basins) como as de Pouso Alegre e similares.

Considerando-se que as porções orientais a esses sítios deposicionais ainda se encontravam orogeneticamente ativas, frente ao continuado fechamento do Oceano Adamastor, acredita-se que a penetração dessas águas ocorreu a partir das porções meridionais a ocidentais do Cinturão Ribeira e que, provavelmente, não foram supridas por aquele oceano, mas por um outro situado ocidentalmente aos crátons do Rio de la Plata/Paraná, que DALZIEL (1997) denominou de Oceano "Brazilides", cuja abertura teve início com a divergência entre os crátons do Amazonas/Pampeno em relação aos do São Francisco/Paraná/Rio de la Plata ao redor de $600 \mathrm{Ma}$. Para isso, é plausível supor que tais águas avançaram primeiramente sobre as porções meridionais do Bloco Paraná que se encontravam relativamente subsidentes frente ao Cráton do Rio de la Plata.

Baseando-se nas concepções de CORDANI et al. (1984) e de SOARES (1987) de que existia uma autonomia do Bloco Paraná com relação ao do Rio de la Plata, e nos dados expostos por CAMPOS NETO (2000), que dão conta da existência de um alinhamento geofísico, com direção NW, situado na altura do que hoje é a cidade de Porto Alegre (RS) e que expressa o encontro de curvas gravimétricas relativamente baixas (adelgaçamento crustal) no embasamento sotoposto à Bacia do Paraná, invocase que essas regiões limítrofes entre blocos foram preferenciais para a penetração de águas oceânicas e para a instalação de mares epicontinentais em áreas do Cinturão Ribeira.

Baseando-se nas correlações estratigráficas e bioestratigráficas entre as bacias que ocorrem ao longo do Cinturão Ribeira, TEIXEIRA (2000) considerou que os depósitos carbonático-terrígenos de Cajamar (HACHIRO \& SANTORO 1996) seriam representativos de áreas plataformais rasas que se estenderam à frente das faixas móveis e em comunicação mais direta com o mar aberto, uma vez que seus depósitos mostram evidências que os denotam como mais susceptíveis aos processos de ressurgências oceânicas (pink dolomites e clastos 
fosfáticos). A presença do foraminífero ancestral Titanotheca coimbrae GAUCHER \& SPRECHMANN 1999 nos depósitos de Cajamar e em outros eminentemente terrígenos (Eleutério e Pico de Itapeva), situados em regiões mais interiores do Cinturão Ribeira, permite correlacioná-los entre si e com os depósitos do Grupo Arroyo del Soldado, no Uruguai, desenvolvido em bacia de margem passiva nas porções orientais do Cráton do Rio de la Plata. Entretanto, tal margem passiva tinha como mar aberto o Oceano Adamastor (HARTNADY et al. 1985). Considerando-se a especificidade do microfóssil e a sua distribuição paleogeográfica, até então restrita às bacias mencionadas, torna-se plausível supor que pelas regiões limítrofes entre os crátons do Rio de la Plata e do Paraná também se estabeleceu uma conexão entre os oceanos Brazilides e Adamastor. Tendo-se como referência o microfóssil esqueletal Cloudina riemkeae, que ocorre nas bacias de Eleutério e do Pico de Itapeva, as correlações bio- e cronoestratigráficas poderiam ser estendidas entre os depósitos de Pouso Alegre e similares do Cinturão Ribeira com os depósitos dos grupos Arroyo del Soldado (Uruguai), Corumbá (MS) e Nama (Namíbia), nos quais o microfóssil foi descrito.

Desse modo, apresenta-se tentativamente uma configuração paleogeográfica (FIGURA 15) para o desenvolvimento da bacia de Pouso Alegre e similares do Cinturão Ribeira no contexto da evolução geológica do Gondwana Ocidental, que espelha o intervalo de 570-540 Ma. Nesse esboço de configuração paleogeográfica, compilado e modificado de BRITO NEVES et al. (1999) e de CAMPOS NETO (2000), a sedimentação teve início após o evento glacial Varanger e os finais do magmatismo principal que acompanhou os processos orogenéticos regionais e se estendeu até cerca de $580 \mathrm{Ma}$ (como no Cinturão Itu, VLACH et al. 1990). O final da sedimentação, por sua vez, ocorreu com a inversão e encurtamento dessas bacias e o fechamento quase completo dos oceanos, dando início aos estágios finais da consolidação do Gondwana Ocidental que perdurou até cerca de $490 \mathrm{Ma}$ (BRITO NEVES et al. 1999, SCHMITT et al. 1999 e CAMPOS NETO 2000 , entre outros).

\section{CONCLUSÕES}

A sedimentação na bacia de Pouso Alegre ocorreu em leques aluviais subaéreos que, nas suas porções distais, atingiam corpo d'água marinho gerando construções deltaicas cujas frentes avançavam até regiões de plataforma proximal, onde foi efetivo o retrabalhamento dos depósitos por correntes de marés e ondas de tempestades. A presença de acritarcos e de cristais de pirita em ritmitos silto-argilo-arenosos da unidade intermediária (offshore) apontam, respectivamente, condições de águas oxigenadas a pouco oxigenadas em regiões de águas relativamente mais profundas, a par da calmaria tectônica.

Dada a proximidade geográfica e o contexto geológico comum do Cinturão Alto Rio Grande, a correlação mais direta com a bacia de Pouso Alegre ocorreria com a bacia de Eleutério, cuja sedimentação teve intervalo de duração melhor aferido, devido à ocorrência em seus depósitos do microfóssil Cloudina, com espectro de existência mundialmente reconhecido ao redor de 570-540 Ma. Com as demais bacias eminentemente terrígenas do sul-sudeste do país, as correlações puderam ser realizadas levandose em conta as similaridades estratigráficas, mormente os estilos e ambientes deposicionais, além do intervalo mais amplo estimado para a sedimentação, situada entre $600-530 \mathrm{Ma}$, obtido a partir de datações absolutas em rochas do embasamento e nos depósitos dessas bacias.

Considerando-se o contexto tectônico de evolução do Gondwana Ocidental, as regiões ocidentais do Orógeno Mantiqueira, em particular, encontravam-se relativamente estabilizadas frente aos processos de colagem tectônica e magmatismo inerente, o que propiciou ali a instalação de embaciamentos (strike-slip basins) associados às zonas de cisalhamentos com movimentações laterais oblíquas. Após a glaciação Varanger e a par da variação eustática positiva, nas regiões ocidentais do Cráton do Paraná desenvolveram-se, provavelmente, margens continentais passivas e, nas regiões interiores subsidentes do cráton as condições foram propícias ao estabelecimento de mares epicontinentais, que viriam constituir nível de base para os embaciamentos em questão. Os depósitos carbonáticos de Cajamar representam, provavelmente, restos de uma plataforma mais ampla, porta de entrada das águas oceânicas.

Considerando-se os intervalos para a idade da sedimentação e as correlações estratigráficas e paleontológicas, tornou-se possível, com a adoção de uma modelagem paleotectônica e paleogeográfica modificada da literatura, aventar a hipótese de que as bacias da transição do sulsudeste tiveram suas águas marinhas supridas pelo Oceano Brazilides, que se expandia concomitante à 


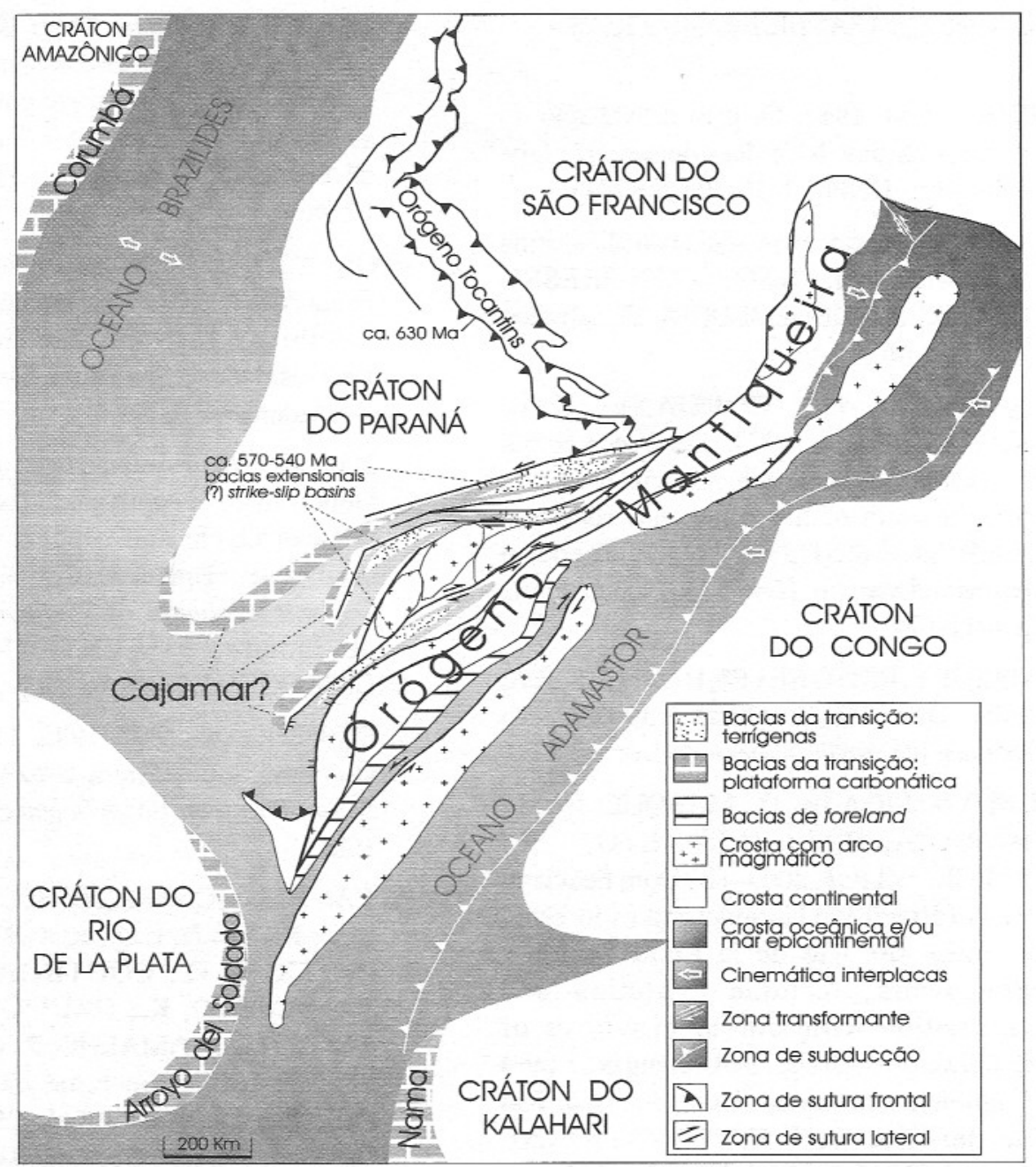

FIGURA 15 - contexto geotectônico e paleogeográfico de parte do Gondwana Ocidental (ca. 570-540 Ma) para a evolução das bacias da transição Neoproterozóico-Cambriano. Compilado e modificado de BRITO NEVES et al. 1999 e CAMPOS NETO (2000).

divergência dos crátons do Amazonas/Pampeano e do São Francisco/Paraná. Nas regiões meridionais do Cráton do Paraná e setentrionais do Cráton do Rio de la Plata, foi estabelecida a conexão entre os oceanos Brazilides e Adamastor, este último em franco processo de fechamento, graças à convergência dos crátons do São Francisco/Paraná (Rio de la Plata) e do Congo/Kalahari. Tal conexão permitiu a disseminação de microfósseis, destacadamente a Cloudina, que se tornaram comuns às bacias dos vários continentes.

A inversão e encurtamento da bacia de Pouso Alegre e das demais bacias correlatas ocorreram com o fechamento dos oceanos Brazilides e Adamastor, a par da convergência geral entre os referidos crátons, refletindo nas assinaturas isotópicas $\mathrm{K}-\mathrm{Ar}$ de rochas do embasamento e dos metassedimentos das bacias, situadas ao redor de $530 \mathrm{Ma}$.

\section{AGRADECIMENTOS}

Os autores agradecem à FAPESP pelo apoio financeiro dispensado para a realização do projeto de pesquisa "Análise das bacias da transição Proterozóico-Fanerozóico do Estado de São Paulo e adjacências" (Processos 97/01013-4 e 99/124257). Agradecem também à Revista do Instituto Geológico pela oportunidade da publicação deste artigo, bem como aos seus consultores anônimos pelas enriquecedoras críticas e sugestões para a conclusão deste trabalho. 


\section{REFERÊNCIASBIBLIOGRÁFICAS}

ALMEIDA, F.F.M. 1967. Origem e evolução da plataforma brasileira. Rio de Janeiro: Div. Geol. Min-DNPM, 1-36(Boletim 241).

1969. Diferenciação tectônica da plataforma brasileira. In: SBG, CONGRESSO BRASILEIRO DE GEOLOGIA, 23, Salvador, Anais, 29-46.

; AMARAL, G.; CORDANI, U.G.; KAWASHITA, K. 1973. The Precambrian evolution of the South American Craton margin south of the Amazonas river. In: NAIRN, A.E. \& STEHLI, F:G. (ed.) The ocean basins and margins. New York, Plenum Press, p. 1411-1446.

; HASUI, Y.; BRITO NEVES, B.B.; FUCK, R.A. 1981. Brazilian structural provinces: An introduction. Earths Science Reviews, 17: 1-29.

BASEI, M.A.S.; SIGA JR., O.; MASQUELIN, H.; HARARA, O.M.; REIS NETO, J.M.; PRECIOZZI P., F. 2000. The Dom Feliciano Belt of Brazil and Uruguay and its foreland domain, the Rio de la Plata Craton Framework, tectonic evolution and correlation with similar provinces of Southwestern Africa. . In: Cordani et al. (ed.) Tectonic evolution of South America. Rio de Janeiro, $31^{\text {st }}$ INTERNATIONAL GEOLOGICAL GONGRESS, p. 311-334.

BOGGIANI, P.C. 1998. Análise estratigráfica da bacia Corumbá (Neoproterozóico) - Mato Grosso do Sul. Instituto de Geociências, Universidade de São Paulo, São Paulo, Tese de Doutoramento, 181p.

BROWRING, S.A.; GROTZINGER, J.P.; ISACHSEN, C.E.; KNOLL, A.H.; PELECHATY, S.M.; KOLOSOV,P. 1993. Calibrating rates of Early Cambrian evolution. Science, 261: 1293-1298

BRITONEVES, B.B.; CAMPOSNETO,M.C.; FUCK, R.A. 1999. From Rodinia to Western Gondwana: An approach to the BrasilianoPan African Cycle and orogenic collage. Episodes, 22(3): 155-166.

CAMPANHA, G.A.C.; SADOWSKI, G.R. 1999. Tectonics of the southern portion of the Ribeira Belt (Apiaí Domain). Precambrian Research, 98: 31-51

; FERNANDES, L.A.; GIMENEZ FILHO, A. 1982. Mapeamento geológico na escala
1:50.000 das folhas Mogi-Guaçu (parte correspondente ao embasamento cristalino) e Águas de Lindóia (parte correspondente ao Estado de São Paulo). São Paulo: Instituto de Pesquisas Tecnológicas (Rel. IPT $\mathrm{n}^{\circ}$. 17.446).

CAMPOS NETO, M.C. 1991. A porção ocidental da Faixa Alto Rio Grande - ensaio de evolução tectônica. Instituto de Geociências, Universidade de São Paulo, São Paulo, Tese Doutoramento, 210p.

2000. Orogenic systems from southwestern Gondwana. An approach to Brasiliano-Pan African Cycle and orogenic collage in southeastern Brazil. In: Cordani et al. (ed.) Tectonic evolution of South America. Rio de Janeiro, $31^{\text {sT }}$ INTERNATIONAL GEOLOGICAL GONGRESS, p. 335-365.

; FIGUEIREDO, M.H. 1995. The Rio Doce Orogeny, Southeastern Brazil. Journal of South American Earth Sciences, 8(2): 143162.

CAVALCANTE, J.C.; CUNHA, H.C.S.; CHIEREGATI, L.A.; KAEFER, L.Q.; ROCHA, J.M. DA; DAITX, E. C.; COUTINHO, M.G.N.; YAMAMOTO, K.; DRUMOND, J.B.V.; ROSA, D.B.; RAMALHO, R. 1979. Projeto Sapucaí (Relatório Final de Geologia). Brasília: DNPM/CPRM. 299p. (Série Geologia, 5; Seção Geologia Básica, 2)

CORDANI, U.G.; BRITONEVES, B.B.; FUCK, R.A.; PORTO, R.; THOMAZ FILHO, A.; CUNHA, F.M.B. 1984. Estudo preliminar de integração do Pré-Cambriano com os eventos tectônicos das bacias sedimentares brasileiras. Rio de Janeiro: PETROBRÁS (CENPES/SINTEP), 70 p. (Série CiênciaTécnica-Petróleo. Seção: Exploração de Petróleo. Publ. $n^{\circ} 15$ )

DALZIEL, I.W.D. 1997. Neoproterozoic-Proterozoic geography and tectonics: review, hypothesis, environmental speculation. GSA Bulletin, 109 (1): 16-42.

EBERT, H. 1968. Ocorrência de fácies granulítica no sul de Minas e em áreas adjacentes, em dependência da estrutura orogênica: hipótese sobre sua origem. Rio de Janeiro: Anais da Academia Brasileira de Ciências, 40 (suplemento): 215-229

1971. Os Paraibides entre São João del Rei, Minas Gerais e Itapira, São Paulo e a 
bifurcação entre Paraibides e Araxaídes. In: SBG, CONGRESSO BRASILEIRO DE GEOLOGIA, 25. São Paulo, Resumo das Comunicações, 177-178 (Boletim Especial, 1)

GAUCHER, C. 2000. Sedimentology, palaeontology and stratigraphy of the Arroyo del Soldado Group (Vendian to Cambrian, Uruguay). Würzburg: Beringeria, 24: 1-150

; SPRECHMANN, P. 1999. Upper Vendian skeletal fauna of the Arroyo del Soldado Group, Uruguay. Würzburg: Beringeria, 23: 55-91

; SCHIPLOV, A. 1996. Upper and Middle Proterozoic fossiliferous sedimentary sequences of the Nico Pérez Terrane of Uruguay: Lithoestratigraphic units, paleontology, depositional environments and correlations. N. Jb. Geol. Paläont. Abh., 199 (3): 339-367

GERMS, G. 1972. New shelly fossils from Nama Group, South West Africa. American Journal of Science, 272: 752-761

1974. The Nama Group in South West Africa and its relationship to the Pan-African Geosyncline. Journal of Geology, 82: 301317

1995. The Neoproterozoic of southwestern Africa, with emphasis on platform stratigraphy and paleontology. Precambrian Research, 73: 137-151

GROTZINGER, J.P.; BOWRING, S.A.; SAYLOR, B.Z.; KAUFMAN, A.J. 1995. Biostratigraphic and geochronologic constraints on early animal evolution. Science, 270: 598-604

HACHIRO, J.; SANTORO, E. 1996. Uma provável bacia terrígeno-carbonática de idade neoproterozóico-eopaleozóica, em Cajamar (SP). Anais da Academia Brasileira de Ciências, 68(4): 601

HAMA, M.; CUNHA, H.C.S. 1977. Consideração sobre a idade da Formação Pouso Alegre e dos granitos pós-cambrianos na região sul de Minas Gerais e nordeste do Estado de São Paulo. In: SBG, SIMPÓSIO REGIONAL DE GEOLOGIA, 1. São Paulo, Atas, 48-58

HARTNADY, C.J.H.; JOUBERT, P.; STOWE, C. 1985. Proterozoic crustal evolution of Southwestern Africa. Episodes, 8: 236-244

HASUI, Y. 1982. The Mantiqueira Province: Archaean structure and Proterozoic evolution. São Paulo: Revista Brasileira de Geociências, 12(1,2,3): 167-172

KNOLL, A.H. 1996. Daughter of time. Chicago: Paleobiology, 22:1-7.

LEONARDOS JR., O.H.; DUNHAM, A.C.; PIRES, F.R.M.; FORMAN, J.M.A. 1971. Nota sobre a Formação Pouso Alegre. Anais da Academia Brasileira de Ciências, 43: 131143

MCMENAMIN, M.A.S.; MCMENAMIN, D.L.S. 1990. The emergence of animals: the Cambrian breakthrouggh. New York, Columbia University Press, $217 \mathrm{p}$.

MCPHERSON, J.G.; SHANMUGHAM, G.; MOIOLA, R.J. 1987. Fan deltas and braid deltas: varieties of coarse-grained deltas. Geol. Soc. Am. Bull., 99: 331-340

MEERT, J.G.; VAN DER VOO, R. 1994. The Neoproterozoic (1000-540 Ma) glacial intervals: No more snowball earth? Earth and Planetary Science Letters, 123: 1-13.

MORAIS, S. M. 1999. Programa Levantamentos Geológicos Básicos do Brasil: Integração geológica da Folha Guaratinguetá. Escala 1:250.000 SF.23-Y-B. Estados de São Paulo e Minas Gerais. São Paulo, CPRM. 25p.

NARBONNE, G.M.; SAYLOR, B.Z; GROTZINGER, J.P. 1997. The youngest ediacaran fossils from Southern Africa. J. Paleont., 71(6): 953-967

PIMENTEL, M.M.; WHITEHOUSE, M.J.; VIANA, M.G.; FUCK, R.A.; MACHADO, N. 1997. The Mara Rosa arc in the Tocantins Province further evidence for Neoproterozeic crustal accretion in Central Brazil. Precambrian Research, 81:299-310.

PORADA, H. 1979. The Damara-Ribeira Orogen of the Pan-African-Brazilian cycle in Namibia (South West Africa) and Brazil as interpretation in terms of continental collision. Tectonophysics, 57: 237-265

POWELL, C.M. 1995. Are Neoproterozoic glacial deposits preserved on the margins of Laurentia related to the fragmentation of two continents? - Comments. Geology, 23: 1053 1054.

RICCOMINI, C. 1993. Origem, evolução e inversão da bacia do Pico de Itapeva, Neoproterozóico-Cambriano, São Paulo, Brasil. In: DINAMIGE-Fac. Agron., SIMPÓSIO INTERNACIONAL DEL 
NEOPROTEROZOICO-CAMBRICODELA CUENCA DEL PLATA, 1. La Paloma-Minas, Resumenes Extensos, Tomo I, res. 16.

SANTORO, E. 1998. Evolução geológica do PréCambriano da região de Santo Antonio do Pinhal, SP: importância tectônica das zonas de cisalhamento. Instituto de Geociências, Universidade de São Paulo, São Paulo, Tese de Doutoramento, $153 \mathrm{p}$.

; SILVA M.E. 1999. Processos deformacionais brasilianos na região de Santo Antonio do Pinhal, SP. Anais da Academia Brasileira de Ciências, 71(4): 839-840.

SCHMITT, R.S; TROUW, R.A.J.; VAN SCHMUS, W.R. 1999. The characterization of a Cambrian $(\sim 520 \mathrm{Ma})$ tectonometamorphic event in the coastal domain of the Ribeira Belt (SE Brazil) - using $\mathrm{U} / \mathrm{Pb}$ in syntectonic veins. In: SOUTH AMERICAN SYMPOSIUM ON ISOTOPE GEOLOGY, II, Argentina, Actas, 363-366

SOARES, P.C. 1976. Projeto Caldas II: Geologia das quadrículas de Santa Rita de Caldas e Ipuiúna (Relatório Final). Rio Claro: Convênio Depto. Geoc.-FFCL/UNESP - DNPM, 48p.

1987. Seqüências tecto-sedimentares e tectônica deformadora no centro-oeste do Escudo Paranaense. In: SBG, SIMPÓSIO SUL BRASILEIRO DE GEOLOGIA, 3. Curitiba, Atas, 2: 743-771

TEIXEIRA, A.L. 1995. Ambientes geradores dos sedimentos da bacia Eleutério. Instituto de Geociências, Universidade de São Paulo, São Paulo, Dissertação de Mestrado, 132p.

2000. Análise das bacias da transição Proterozóico-Fanerozóico do Estado de São Paulo e adjacências. Instituto de Geociências, Universidade de São Paulo, São Paulo, Tese de Doutoramento, $158 \mathrm{p}$.

; GAUCHER, C. 2001. Litoestratigrafia, Paleontologia y correlaciones de las cuencas de Eleutério, Pouso Alegre, Pico de Itapeva y Cajamar (Vendiano-Cambrico), Brasil. In: DINAMIGE/SUG, CONGRESO
LATINOAMERICANO DE GEOLOGÍA, 11. Montevidéu, Actas (Ed. Eletrônica), Trabalho $\mathrm{n}^{\circ} 088,4 \mathrm{p}$.

; CORDANI, U.G.; NUTMAN, A. 1999. Idades $\mathrm{U} / \mathrm{Pb}$ (SHRIMP) de seixo riolítico em metaconglomerado da bacia Eleutério, Estado de São Paulo. Anais da Academia Brasileira de Ciências, 71(4): 837-838

TODD, S.P. 1989. Stream-driven, high-density gravelly traction carpets: possible deposits in the Tratberg Conglomerate Formation, SW Ireland and some theoretical considerations of their origin. Sedimentology, 36: 513-530

VASCONCELLOS, A.C.B.C. 1988. Ó Grupo Andrelândia na região a norte de Ouro Fino, MG. Instituto de Geociências, Universidade de São Paulo, São Paulo, Dissertação de Mestrado, 199p.

VLACH, S.R.F.; JANASI, V. A.; VASCONCELLOS, A.C.B.C. 1990. The Itu Belt: associated calcalkaline and aluminous A-type Late Brasiliano granitoids in the states of São Paulo and Paraná, southern Brazil. In: SBG, CONGRESSOBRASILEIRODEGEOLOGIA, 36. Natal, Anais, 4: 1700-1711.

WALDE, D.H.G.; LEONARDOS, O.H.; HAHN, G.; HAHN, R.; PFLUG, H. 1982. The first Precambrian megafossil from South America, Corumbella werneri. Anais da Academia Brasileira de Ciências, 54(2): 461

WINKLER, H.G.F. 1976. Petrogenesis of Metamorphic Rocks. $4^{\text {th }}$ ed. 348p. New York, Springer-Verlag.

ZAINE, M.F. 1991. Análise dos fósseis de parte da Faixa Paraguai (MS, MT) e seu contexto temporal e paleoambiental. Instituto de Geociências, Universidade de São Paulo, São Paulo, Tese de Doutoramento, 218p.

; FAIRCHILD, T.R. 1985. Comparison of Aulophycus lucianoi Beurlen \& Sommer from Ladário (MS) and the genus Cloudina Germs, Ediacaran of Namibia. Anais da Academia Brasileira de Ciências, 57: 130.

Endereço dos autores:

Antonio Luiz Teixeira - Instituto Geológico - SMA, Avenida Miguel Stéfano, 3900, CEP 04301-903, São Paulo, SP Brasil.E-mail: candeias@igeologico.sp.gov.br

Setembrino Petri - Instituto de Geociências, Departamento de Geologia Sedimentar e Ambiental, Universidade de São Paulo, Rua do Lago, 562, CEP 05508-900, São Paulo, SP - Brasil. E-mail: spetri@usp.br 